\title{
Guiding and interpreting brain network classification with transcriptional data
}

Mengbo $\mathrm{Li}^{1,2}$, Daniel Kessler ${ }^{3,4}$, Jesús Arroyo ${ }^{5}$, Saskia Freytag ${ }^{6,7}$, Melanie Bahlo ${ }^{6,7}$, Elizaveta Levina $^{3}$ and Jean Yang ${ }^{1,2, *}$

${ }^{1}$ School of Mathematics and Statistics, Faculty of Science, the University of Sydney, NSW 2006, Australia

${ }^{2}$ Charles Perkins Centre, the University of Sydney, NSW 2006, Australia

${ }^{3}$ Department of Statistics, University of Michigan, Ann Arbor, MI 48109, USA

${ }^{4}$ Department of Psychiatry, University of Michigan, Ann Arbor, MI 48109, USA

${ }^{5}$ Center for Imaging Science, Johns Hopkins University, Baltimore, MD 21218, USA

${ }^{6}$ Population Health and Immunity Division, The Walter and Eliza Hall Institute of Medical Research, Parkville, VIC 3052, Australia

${ }^{7}$ Department of Medical Biology, University of Melbourne, Parkville, VIC 3052, Australia

* To whom correspondence should be addressed. Email: jean.yang@sydney.edu.au. 


\section{Abstract}

The investigation of brain networks has yielded many insights that have helped to characterise many neurological and psychiatric disorders. In particular, network classification of functional magnetic resonance imaging (fMRI) data is an important tool for the identification of prognostic and diagnostic biomarkers of brain connectivity disorders such as schizophrenia and depression. However, existing generic network classification methods provide no direct information on the underlying molecular mechanisms of the selected functional connectivity features when applied to $\mathrm{fMRI}$ data. To address this, we propose a novel fMRI network classification method that incorporates brain transcriptional data using a user-specified gene set collection (GSC) to construct feature groups for use in classification of brain connectivity data. The use of GSCs are an opportunity to incorporate knowledge of potential molecular mechanisms which may be associated with a disease. The inclusion of transcriptional data yields improved prediction accuracy on publicly available schizophrenia fMRI data for several of the GSCs we consider. We also introduce a post-hoc interpretation framework to provide transcriptional-data-guided biological interpretations for discriminative functional connectivity features identified by existing fMRI network classification methods.

\section{Introduction}

Network analysis of functional brain imaging data has been widely applied in studies of neurological disorders and has facilitated the discovery of functional biomarkers in many complex brain diseases $[6,10,39]$, but the molecular and neurobiological mechanisms underlying brain functional connectivity patterns remain elusive [36, 37]. Previous studies [23, 37, 43] on neuroimaging network classification in mental disorders that provided feature selection typically sought to biologically interpret algorithmically selected functional connectivity features post hoc, based on available literature on the known functions of certain brain regions. At the same time, it is known that differential transcription across distinct brain regions has an impact on brain functions [20, 30], raising the question of how changes in gene expression associated with a mental disorder may 
be connected to disrupted brain functional organisation (note that in this paper we sometimes use the phrase "gene expression" when discussing transcriptional data). Recent work [30, 34] analysed transcriptional networks that focused on gene-gene correlations across distinct brain regions, and gene ontology enrichment analyses were used to assess the functional relevance of identified gene modules, but these studies did not examine the associated changes in functional connectivity patterns.

Traditionally, integrative analysis on multimodal data requires measurements of different modalities from the same cohort of subjects. For instance, genome-wide association studies (GWAS) on brain imaging phenotypes require subject-matched structural or functional magnetic resonance imaging (fMRI) scans and genome-wide genetic data. However, functional imaging and antemortem transcriptional data are highly unlikely to be available from the same brain at the same time as expression assays require invasive access to brain tissues [2]. A recent paper [12] reviewed common approaches to link the functional connectome with the whole brain transcriptome from the Allen Human Brain Atlas (AHBA), an anatomically comprehensive human brain transcriptional atlas [19]. They include testing for correlations between measurements of brain imaging based disease phenotypes and (i) the spatial transcriptional profiles of a particular gene, (ii) eigengenes of disease associated pathways or gene ontology terms [4], or (iii) the spatial expression patterns of known risk genes. Another approach is to perform gene set enrichment tests on genes previously found to be associated with normative imaging phenotypes of the disease since many genes are functionally related [12]. Although these methods only provide a list of priority genes for further study, there is evidence that spatial variations in brain transcriptional profiles closely track variations in functional organisation of the brain [12].

Here, we introduce a transcriptional-data-guided functional network classification method to enable biologically annotated feature selection in functional brain network classification via the regional matching of multimodal data. Our case study on the publicly available data set shows that transcriptional-data-guided classification of functional connectivity facilitates the identification of underpinning molecular mechanisms for disrupted functional organisations in complex neurological diseases. 


\section{Materials and Methods}

\section{Data sets}

Processed resting state $\mathrm{fMRI}$ networks for subjects (54 schizophrenic and 70 healthy control) from the Center for Biomedical Research Excellence (COBRE) schizophrenia fMRI data [1, 41] were downloaded from the graphclass $R$ package [3]. Whole brain microarray gene expression data were downloaded from the Allen Human Brain Atlas (AHBA) at http://human.brainmap.org/static/download?rw=t. Both COBRE fMRI data and AHBA microarray gene expression samples were registered to the MNI152 1mm space during initial data pre-processing. Gene set information was downloaded from the Molecular Signatures Database (MSigDB, v7.0) [26]. Gene-schizophrenia association scores were obtained from DiGSeE [24], a MEDLINE abstract text mining search engine.

\section{Data processing}

Regions of interest (ROIs) from the Power et al. brain parcellation [35] were used as nodes to construct the brain networks. Time course data were extracted from the ROls defined by the Power parcellation. The 1,488 AHBA gene expression samples were also mapped to the same brain parcellation and assigned to ROls. Out of the 264 ROls in the Power parcellation, 248 had at least one AHBA sample mapped to it. The remaining 16 ROls which had no AHBA samples mapped to them were excluded from our transcriptional-data-guided method, but retained for use in other methods that do not directly depend upon transcriptional data (e.g., the baseline network classifiers and the post-hoc interpretation framework proposed below). ROI 75 was also discarded as it is missing in COBRE data. In summary, 247 ROls with mapped transcriptional profiles were used as nodes to construct each transcriptional brain network. Details on the AHBA brain tissue sample to Power ROI mapping, as well as other gene expression data processing steps, are provided in Supplementary Methods.

brainClass: Transcriptional-data-guided brain network classification

The proposed classification method has two major components, both with several steps. 
(A) Construction of Gene Set Edge Groups (Figure 1a). The transcriptional data is first partitioned by a gene set collection (GSC) under consideration. A weighted, undirected ROI-wise transcriptional network is then calculated for each gene set from the GSC as follows. In the transcriptional network of gene set $x$, the weight $w_{i j}^{x}$ of an edge $(i, j)$ between ROls $i \neq j$ is computed as the absolute value of the Pearson correlation coefficient of the gene expression levels of genes in set $x$ between ROI $i$ and ROI $j$. Next, a very stringent hard-thresholding criterion is applied to obtain a subset of the highest-weighted edges in each network, defined by

$$
E_{\mathrm{GS}_{x}}=\left\{(i, j) \mid w_{i j}^{x} \geq \eta_{0.99}, i \neq j\right\}
$$

where $\eta_{0.99}$ is the 99th percentile of all edge weights in this network.

(B) fMRI Network Classification (Figure 1b) For each subject, the fMRI network is constructed using the Power ROIs as nodes. The Pearson correlation coefficient of the fMRI time courses between ROls is used as the connectivity measure between nodes. Edge weights of each fMRI network are treated as a long feature vector in classification. See Supplementary Methods for details regarding $\mathrm{fMRI}$ data.

For fMRI network classification, we make use of statistical classification methods that perform feature selection among overlapping feature groups. Functional edges are grouped according to the gene set edge groups constructed in component $(A)$ to form (potentially overlapping) feature groups, and edges that do not belong to any feature group are excluded from training. The current default implementation of brainClass uses logistic regression with the overlapping group lasso penalty implemented in the grpregOverlap R package [42], which allows user-defined overlapping feature groups.

Gene Set Prioritisation With feature selection results from classification, gene sets within a given GSC can be ranked by any user-defined gene set prioritisation score to quantify their relevance to functional connectivity. In the current implementation, we utilise a measure for overlap defined as

$$
\frac{\left|E_{\mathrm{fMRI}} \cap E_{\mathrm{GS}_{x}}\right|}{\left|E_{\mathrm{GS}_{x}}\right|}
$$


for each gene set $x$, where $|\cdot|$ denotes the cardinality of a set, and $E_{\mathrm{fMRI}}$ is defined as the set of edges selected (with a non-zero fitted coefficient) in each fold of a 10-fold cross-validation. Gene sets ranked in top $5 \%$ by the above measure in all ten folds in all 50 repetitions of 10 -fold cross-validations are considered prioritised in the GSC of interest.

\section{Evaluation of brainClass}

Selection of GSC The performance of brainClass was evaluated when various types of GSCs were used for the construction of gene set edge groups. The proposed algorithm was also evaluated when non-informative gene sets were utilised, as discussed below. Non-informative GSCs were generated with 606 gene sets each, which is the median size of all evaluated biologically meaningful GSCs (Figure 2c). The size of each individual gene set was randomly drawn from the distribution of all gene set sizes shown in Figure 2c, regardless of the category.

\section{Post-hoc interpretation framework}

We propose a framework for the post-hoc interpretation of an edge set selected by a classifier (see Figure 2 for a schematic overview). Let $E_{\mathrm{fMRI}}$ denote the set of edges selected by an fMRI network classifier, consisting of edges with a non-zero estimated coefficient. As a post-hoc interpretation metric, we can compare the edge sets $E_{\mathrm{fMRI}}$ and $E_{\mathrm{GS}}$, the subset of highest-weight edges in the transcriptional connectivity network of gene set $x$. We measure their similarity by the Jaccard index, defined as

$$
J_{G S_{x}}=\frac{\left|E_{\mathrm{fMRI}} \cap E_{\mathrm{GS}_{x}}\right|}{\left|E_{\mathrm{fMRI}} \cup E_{\mathrm{GS}_{x}}\right|} .
$$

We then repeatedly select $n=\left|E_{\mathrm{fMRI}}\right|$ edges at random from the set of all possible edges to obtain a null distribution for the Jaccard index and an estimated $P$-value for $J_{G S_{x}}$.

Another metric is devised based on the edge betweenness centrality, defined as the number of the shortest paths via the edge in a network [16]. Because the strict threshold we previously applied resulted in highly disconnected graphs, we instead apply a less stringent threshold to obtain a 
binary transcriptional network of gene set $x$ :

$$
w_{i, j}^{x^{\prime}}=\mathbb{I}\left(w_{i, j}^{x} \geq \eta_{0.75}\right), i \neq j
$$

where $\eta_{0.75}$ is the $3 r d$ quartile of all edge weights $\mathbf{w}^{x}$, retaining $25 \%$ of edges with the highest weights instead of $1 \%$ as we did before. For this network, we calculate the average edge betweenness centrality for the edges that also belong to $E_{\mathrm{fMRI}}$, for each gene set $x$. We then generate a null distribution by randomly choosing $n=\left|E_{\mathrm{fMRI}}\right|$ edges to serve as the pseudo $E_{\mathrm{fMRI}}$ set and repeat the above procedure: we intersect each $E_{\mathrm{GS}}$ with the pseudo $E_{\mathrm{fMRI}}$ set and calculate the average edge betweenness centrality of these edges. We use this null distribution to obtain an estimated $P$-value for each gene set. We use the Jaccard index, the average edge betweenness, and the $P$-values associated with each to rank gene sets. The same approach is applicable to any other user-defined interpretation metric.

\section{Application of the post-hoc interpretation framework to COBRE data}

Feature selection results evaluated by the post-hoc interpretation framework We compared the functional edge selection results of our method to the two existing fMRI network classification methods we use as benchmarks. For logistic regression with the ordinary lasso penalty, glmnet [14], $E_{\mathrm{fMRI}}$ was defined as the set of edges selected (with a non-zero fitted coefficient) in at least one fold of at least ten of the 50 repetitions of 10 -fold cross validation. For the overlapping lasso penalty in graphclass [3], as recommended by the authors, stability selection [27] was used to calculate variable selection probabilities, by randomly splitting the data and calculating the percentage of times across all random splits that each variable was chosen. Edges chosen more than half the time were selected.

Evaluation procedure The effectiveness of different GSCs in explaining the functional edge selection results by other existing fMRI network classifiers were evaluated. Schizophrenia relevance scores were constructed for each gene set based on the gene-schizophrenia association scores extracted from DiGSeE [24] and log-transformed. We consider both (i) the sum of gene-based disease association scores (for identifying gene sets driven by a small number of strong effects) and 
(ii) the average disease association score for each set. Within each GSC, gene sets with a top $5 \%$ sum score or a top $5 \%$ average score were categorised as the true positives, or in other words, to be associated with schizophrenia, and true negatives otherwise (Figure $2 b$ ). The accuracy of gene set categorisation by each interpretation metric was evaluated by the receiver operating characteristic $(\mathrm{ROC})$ curve constructed with a step size of $5 \%$, where the true positive rate is plotted against the false positive rate, and the corresponding area under the curve (AUC). This procedure was repeated to obtain a distinct AUC score for each combination of GSC and classifier.

\section{Results}

brainClass: A new method for brain network classification guided by transcriptional data

Our novel fMRI network classification method, brainClass, uses gene expression across brain regions to guide connectivity-based feature selection, with the goal of bridging the gap between the functional biomarkers of neurological disorders and their underpinning molecular mechanisms. Firstly, brain regional matching is performed between whole brain transcriptional data and fMRI data via the spatial coordinates of each sample with the aid of a standardised brain template (e.g., MNI152 1mm). Both modalities of data are then mapped into a selected brain parcellation, where the pre-defined ROls are used as nodes to construct both transcriptional and fMRI networks. Next, feature groups are strategically constructed and annotated to incorporate the biologically relevant gene set information, such as pre-defined biological pathways or gene ontology (GO) terms [4]. Finally, we perform network classification using statistical classification methods that allow overlapping feature groups.

Application on COBRE data shows the transcriptional-data-guided fMRI network classifier outperformed the baseline methods in terms of the classification accuracy when guided by certain GSCs (Figure 3a). Compared with glmnet (82\%), brainClass implemented with any tested GSCs provided higher classification accuracy except for the positional gene sets (80\%). The average crossvalidation prediction accuracies of brainClass with feature groups constructed via GO molecular function terms (92\%) and filtered GO biological process (only gene sets sized between 10 and 30 were used [22]) terms (94\%) were also higher than that of graphclass (91\%). 


\section{Classification performance depends on the GSC utilised in feature group construction}

Prediction accuracy varied when different GSCs were used, as expected, since classification results depend strongly on feature groups determined by the GSC. Compared with using randomly generated GSCs, Figure 3a shows that the transcription factor targets (TFTs), GO molecular function terms, REACTOME pathways and filtered GO biological process terms outperformed the random GSCs (median accuracies of $89 \%, 92 \%, 91 \%$ and $94 \%$ respectively versus $88 \%$; see the figure for a measure of CV variation around these median accuracies, represented by boxplots).

We observed reasonably high network classification accuracy with a small number of features selected by the baseline classifier of glmnet on the COBRE data. The median classification accuracy over 50 repetitions of 10 -fold cross-validation was $82 \%$ (Figure 3a) for the ordinary lasso via glmnet. The number of unique features selected across 10 folds of each cross-validation repetition ranges from 200 to 300 , out of the total of 34, 453 (263 choose 2) features, or below $1 \%$ on average. On the contrary, for graphclass, almost all features were always selected, to obtain the median estimation of classification accuracy of $91 \%$ (Figure $3 a$ ).

In brainClass, the GSC used in feature group construction influences the number of selected features by the proposed method. For example, 14,721 functional edges were included in training by the positional GSC and 7,057 edges by the GSC of TFT. In our analysis, the regularisation parameter $\lambda$ of grpregOverlap was tuned to $5 \times 10^{-3}$ so that the implemented algorithm selected around $10 \%$ features that had non-zero coefficients. Although sparse models (with few features selected) commonly have lower prediction accuracy in high-dimensional settings [18], the median prediction accuracy over repeated cross-validation was considerably higher when the proposed classifier was guided by TFT (89\%) than by the positional GSC (80\%). This implies that strategic construction of feature groups can potentially improve prediction accuracy and promote sparsity at the same time. The numbers of features included in training and the distribution of the number of selected features by different GSCs are provided in Supplementary Results.

\section{Quality of biological information affects prediction accuracy of brainClass}

As curated gene set information evolves, the performance of the transcriptional-data-guided fMRI 
network classification algorithm can also improve. The prediction accuracy of brainClass was also evaluated when GSC information was downloaded from the previous release of MSigDB, v6.2 (Figure 3b). The current version (v7.0) implemented a major overhaul in GSCs including the positional gene sets and GO term GSCs compared to the older v6.2. There was also a major update in REACTOME pathways from v6.2 to v7.0, for which the prediction accuracy was improved when the $\mathrm{fMRI}$ network classification was guided by the updated pathway information (from $89 \%$ to 91\%). An even bigger improvement was observed when GO biological process terms (filtered for gene sets sized between 10 and 30 in both versions) were utilised for feature group construction in classification (from $87 \%$ to $94 \%$ ). The positional GSC yielded relatively poor performance ( $87 \%$ in v6.2 and $80 \%$ in v7.0), which is not surprising as we expect limited biologically relevant implications on schizophrenia by the physical location of genes on each chromosome.

\section{Selected features have an inherent biological interpretation}

A major advantage of brainClass is the direct connection between selected connectivity features and their potential molecular underpinnings. By directly comparing the set of selected functional edges with the most highly weighted transcriptional edges in each gene set expression network, gene sets can be ranked by the proposed gene set prioritisation metric. For example, Table 1 shows the gene sets ranked in the top $5 \%$ by the implemented gene set prioritisation metric in each fold of the 50 repeats of 10 -fold cross-validations when brainClass was guided by REACTOME pathways. Note that the DiGSeE gene set scores are not directly used by the brainClass classification method, but displayed here for reference only.

Many of the prioritised REACTOME pathways in Table 1 are associated with schizophrenia as reported in previous studies, such as signaling by GPCR [28, 32, 40], signaling by receptor tyrosine kinases [9, 17], signaling by interleukins [11, 33], and MAPK family signaling cascades [7, 15]. Although scored low by DiGSeE gene set scores, $\mathrm{N}$-Linked glycosylation can play a modulatory role in neural transmission [38], and abnormalities in N-Linked glycosylation potentially indicate disruptions of central cell signaling processes in schizophrenia [29, 31]. Similarly, it has been reported that glucose oxidation, which takes place in the tricarboxylic acid (TCA) cycle, is inherently abnormal in a significant proportion of schizophrenic brains [5] and yet the corresponding REACTOME 
pathway only had low DiGSeE scores. Additional gene set prioritisation results corresponding to other evaluated GSCs are provided in Supplementary Results.

\section{Different network classifiers lead to different post-hoc interpretations}

Functional edge selection results by different classifiers were better interpreted by different GSCs (Figure 2d) in the post-hoc interpretation framework. Edges selected by glmnet were best explained by KEGG pathways, followed by the GO molecular function terms; see Supplementary Table S6 and Figure S7a. In contrast, edges selected by graphclass were better explained by GO molecular function terms, GO biological process terms and REACTOME pathways; see Supplementary Table S7 and Figure S7b.

As expected, GSCs with no obvious involvement in schizophrenia, such as the chromosomal position GSC and the immunological signature GSC, were not helpful in interpreting the functional edge selection results by any classifier. Figure 4 ranks the effectiveness of all examined GSCs by the AUC of each corresponding ROC curve for both classification methods. Generally, GO terms provided better interpretation compared to other GSCs by most of the metrics in both classification methods, and immunologic signatures and positional gene sets on chromosomes provided almost no insight in this case study.

\section{Discussion}

We have devised a novel transcriptional-data-guided fMRI network classification algorithm via the strategic construction of feature groups in order to link transcriptional connectivity with functional connectivity across distinct brain regions with the aid of biologically meaningful gene set information. Application to publicly available data shows that our method provides better prediction accuracy in distinguishing $\mathrm{fMRI}$ networks of schizophrenic patients versus healthy controls while enabling biologically meaningful interpretation for selected functional connectivity features. In addition, we have also provided a post-hoc interpretation framework to enable biologically meaningful interpretation of functional edge selection results by other fMRI network classification algorithms. 
Comparison among feature selection results guided by different GSCs of gene sets suggests there are potentially multiple functional connectivity biomarkers in schizophrenia. For example, two GSCs, GO molecular function terms and the REACTOME pathways, performed similarly well in terms of classification accuracy (Figure 3a) but had very different edge selection results (Supplementary Figure S6). This is by design, since different GSCs use different features and feature groups in training. Thus a biologically meaningful interpretation must consider selected functional connectivity features together with the corresponding GSC used in the construction of feature groups.

The choice of the GSC also affects the computational efficiency of the proposed classifier. Given a set of predictors, the number of feature groups, which depends on the number of gene sets in the selected GSC, increases the computational time of brainClass approximately exponentially. Another tuning parameter that affects the computational efficiency is the hard threshold on edge weights since a stricter cut-off reduces the number of features. An ad hoc investigation suggests that gene set rankings by the gene set prioritisation metric were relatively robust to the choice of the threshold used within a given GSC in our case study.

The ROC-based evaluation of the post-hoc interpretation framework substantially depends on how we construct disease association scores for each gene set. The scores were obtained by taking the sum or the average of association scores provided by DiGSeE for each individual gene after log-transformation, but the collective effect of a group of genes in disease mechanisms may not be additive. Besides, many studies have emphasised the role of pathways or biological processes in the pathogenesis of neurological disorders, rather than individual genes. For example, the WNT signalling pathway has been implicated in many neurodevelopment processes and was reported to be associated with schizophrenia [8,21, 25], but none of these papers were counted towards the DiGSeE score because they do not mention any genes involved in the pathway within their abstracts. Similarly, this suggests that gene set prioritisation results will become more interpretable with the availability of better scoring systems for associations between diseases and molecular signatures such as pathways and GO terms.

One advantage of our framework is its flexibility. This approach can be readily applied for differ- 
ent GSCs, different brain parcellations, and different types of brain network data (e.g., diffusion weighted imaging). In addition, in the post-hoc interpretation framework, one can define different interpretation metrics. One could also utilise gene expression data in different ways to construct different types of feature groups for use in the brainClass method.

\section{Data Availability}

Processed example data and the $\mathrm{R}$ implementation of all proposed methods are available at https://github.com/Mengbo-Li/brainClass.

\section{Acknowledgements}

The authors thank all their colleagues at The University of Sydney, School of Mathematics and Statistics, for their support and intellectual engagement. We also thank Dr. Stephan F. Taylor and his research group at the University of Michigan for assistance with the data set.

\section{Author's contributions}

J.Y.H.Y., E.L., J.A., and D.K. conceived the study. M.L. developed the methods; performed data analysis and implemented the R package with input from J.A., D.K., E.L. and J.Y.H.Y.. J.Y.H.Y. and M.L. interpreted the results with input from J.A. and D.K. D.K., J.A., S.F. and M.B. processed and curated the data. All authors wrote, read and approved the final version of the manuscript.

\section{Funding}

The following sources of funding for each author, and for the manuscript preparation, are gratefully acknowledged: Australian Research Council Discovery Project grant DP170100654 and the NHMRC Career Developmental Fellowship APP1111338 (JYHY); NSF grants 1521551 (EL, JA), 1646108 (EL, DK), 1916222 (EL), and a grant from the Dana Foundation (EL, DK). This work has also been supported by the Faculty of Sciences research funding at University of Sydney. The funding source had no role in the study design; the collection, analysis and interpretation of data; the writing of the manuscript or the decision to submit the manuscript for publication.

\section{Conflict of interest}

None declared. 


\section{References}

[1] Aine,C.J., Bockholt,H.J., Bustillo,J.R., Cañive,J.M., Caprihan,A., Gasparovic,C., Hanlon,F.M., Houck,J.M., Jung,R.E., Lauriello,J. and Liu,J. (2017) Multimodal neuroimaging in schizophrenia: description and dissemination. Neuroinformatics, 15(4), 343-364.

[2] Arnatkevičiūtè,A., Fulcher,B.D. and Fornito,A. (2019) A practical guide to linking brain-wide gene expression and neuroimaging data. Neuroimage, 189, 353-367.

[3] Arroyo Relión,J.D., Kessler,D., Levina,E., and Taylor,S.F. (2019) Network classification with applications to brain connectomics. The Annals of Applied Statistics, 13(3), 1648-1677.

[4] Ashburner,M., Ball,C.A., Blake,J.A., Botstein,D., Butler,H., Cherry,J.M., Davis,A.P., Dolinski,K., Dwight,S.S., Eppig,J.T. and Harris,M.A. (2000) Gene Ontology: tool for the unification of biology. Nature genetics, 25(1), 25-29.

[5] Bubber,P., Hartounian,V., Gibson,G.E. and Blass,J.P. (2011) Abnormalities in the tricarboxylic acid (TCA) cycle in the brains of schizophrenia patients. European Neuropsychopharmacology, 21(3, 254-260.

[6] Bullmore,E. and Sporns,O. (2009) Complex brain networks: Graph theoretical analysis of structural and functional systems. Nature Reviews Neuroscience, 10, 186-198.

[7] Crisafulli,C., Drago,A., Calabrò,M., Spina,E. and Serretti,A. (2015) A molecular pathway analysis informs the genetic background at risk for schizophrenia. Progress in NeuroPsychopharmacology and Biological Psychiatrye, 59, 21-30.

[8] De Ferrari,G.V. and Moon,R.T. (2006) The ups and downs of Wnt signaling in prevalent neurological disorders. Oncogene, 25(57), 7545-7553.

[9] Del Pino,I., García-Frigola,C., Dehorter,N., Brotons-Mas,J.R., Alvarez-Salvado,E., de Lagrán,M.M., Ciceri,G., Gabaldón,M.V., Moratal,D., Dierssen,M. and Canals,S. (2013) Erbb4 deletion from fast-spiking interneurons causes schizophrenia-like phenotypes. Neuron, 79(6), 11521168. 
[10] Eidelberg,D. (2009) Metabolic brain networks in neurodegenerative disorders: a functional imaging approach. Trends in Neurosciences, 32, 548-557.

[11] Ellman, L.M., Deicken, R.F., Vinogradov, S., Kremen, W.S., Poole, J.H., Kern, D.M., Tsai, W.Y., Schaefer, C.A. and Brown, A.S. (2010) Structural brain alterations in schizophrenia following fetal exposure to the inflammatory cytokine interleukin-8. Schizophrenia Researchs, 121(13), 46-54.

[12] Fornito,A., Arnatkevičiūtè,A., and Fulcher,B.D. (2019) Bridging the gap between connectome and transcriptome. Trends in Cognitive Sciences, 23(1).

[13] Freyberg,Z., Ferrando,S.J. and Javitch,J.A. (2009) Roles of the Akt/GSK-3 and Wnt signaling pathways in schizophrenia and antipsychotic drug action. American Journal of Psychiatry, 167(4), 388-396.

[14] Friedman,J., Hastie,T. and Tibshirani,R. (2010) Regularization paths for generalized linear models via coordinate descent. Journal of Statistical Software, 33(1), 1.

[15] Funk,A.J., McCullumsmith,R.E., Haroutunian,V. and Meador-Woodruff,J.H. (2012) Abnormal activity of the MAPK-and cAMP-associated signaling pathways in frontal cortical areas in postmortem brain in schizophrenia. Neuropsychopharmacology, 37(4), 896.

[16] Girvan,M. and Newman,M.E. (2002) Community structure in social and biological networks. Proceedings of the National Academy of Sciences, 99(12), 7821-7826.

[17] Hahn,C.G., Wang,H.Y., Cho,D.S., Talbot,K., Gur,R.E., Berrettini,W.H., Bakshi,K., Kamins,J., Borgmann-Winter,K.E., Siegel,S.J. and Gallop,R.J. (2006) Altered neuregulin 1-erbB4 signaling contributes to NMDA> receptor hypofunction in schizophrenia. Nature Medicine, 12(7), 824.

[18] Hastie,T., Tibshirani,R. and Wainwright,M. (2015) Statistical learning with sparsity: the lasso and generalizations. Chapman and Hall/CRC.

[19] Hawrylycz,M.J., Lein,E.S., Guillozet-Bongaarts,A.L., Shen,E.H., Ng,L., Miller,J.A., Van De Lagemaat,L.N., Smith,K.A., Ebbert,A., Riley,Z.L. and Abajian,C. (2012) An anatomically comprehensive atlas of the adult human brain transcriptome. Nature, 489, 391-399. 
bioRxiv preprint doi: https://doi.org/10.1101/2020.05.15.099028; this version posted May 16, 2020. The copyright holder for this preprint (which was not certified by peer review) is the author/funder, who has granted bioRxiv a license to display the preprint in perpetuity. It is made available under aCC-BY-NC-ND 4.0 International license.

[20] Hawrylycz,M., Miller,J.A., Menon,V., Feng,D., Dolbeare,T., Guillozet-Bongaarts,A.L., Jegga,A.G., Aronow,B.J., Lee,C.K., Bernard,A. and Glasser,M.F. (2015) Canonical genetic signatures of the adult human brain. Nat. Neurosci., 18(12), 1832-1844.

[21] Inestrosa,N.C., Montecinos-Oliva,C. and Fuenzalida,M. (2012) Wnt signaling: role in Alzheimer disease and schizophrenia. Journal of Neuroimmune Pharmacology, 7(4), 788-807.

[22] Jiang,Z. and Gentleman,R. (2007) Extensions to gene set enrichment. Bioinformatics, 23(3), 306-313.

[23] Kazeminejad,A. and Sotero,R.C. (2018) Topological properties of resting-state fMRI functional networks improves machine learning-based autism classification. Frontiers in Neuroscience, 12:1018.

[24] Kim,J., So,S., Lee,H.J., Park,J., Kim,J.J. and Lee,H. (2013) DigSee: Disease gene search engine with evidence sentences (version cancer). Nucleic Acid Res., 41, 510-517.

[25] Lovestone,S., Killick,R., Di Forti,M. and Murray,R. (2007) Schizophrenia as a GSK-3 dysregulation disorder. Trends in Neurosciences, 30(4), 142-149.

[26] Liberzon,A., Subramanian,A., Pinchback,R., Thorvaldsdóttir,H., Tamayo,P. and Mesirov,J.P. (2011) Molecular signatures database (MSigDB) 3.0. Bioinformatics, 27(12), 1739-1740.

[27] Meinshausen,N. and Bühlmann,P. (2006) High-dimensional graphs and variable selection with the lasso. The Annals of Statistics, 34(3), 1436-1462.

[28] Moreno, J.L., Miranda-Azpiazu, P., García-Bea, A., Younkin, J., Cui, M., Kozlenkov, A., BenEzra, A., Voloudakis, G., Fakira, A.K., Baki, L. and Ge, Y. (2016) Allosteric signaling through an mGlu2 and 5-HT2A heteromeric receptor complex and its potential contribution to schizophrenia. Sci. Signal., 9(410), ra5-ra5.

[29] Mueller,T.M., Haroutunian,V. and Meador-Woodruff,J.H. (2014) N-glycosylation of GABA A receptor subunits is altered in schizophrenia. Neuropsychopharmacology, 39(3), 528.

[30] Negi,S.K. and Guda,C. (2017) Resting-state fMRI: A review of methods and clinical applications. Scientific Reports, 7, 1-12. 
[31] Ohtsubo,K. and Marth,J.D. (2006) Glycosylation in cellular mechanisms of health and disease. Cell, 126(5), 855-867.

[32] Niswender,C.M. and Conn,P.J. (2010) Metabotropic glutamate receptors: physiology, pharmacology, and disease. Annual Review of Pharmacology and Toxicology, 50, 295-322.

[33] Paul-Samojedny, M., Kowalczyk, M., Suchanek, R., Owczarek, A., Fila-Danilow, A., Szczygiel, A. and Kowalski, J. (2010) Functional polymorphism in the interleukin-6 and interleukin-10 genes in patients with paranoid schizophrenia-a case-control study. Journal of Molecular Neuroscience, $\mathbf{4 2 ( 1 ) , ~ 1 1 2 - 1 1 9 . ~}$

[34] Parikshak,N.N., Gandal,M.J. and Geschwind,D.H. (2015) Systems biology and gene networks in neurodevelopmental and neurodegenerative disorders. Nature Reviews Genetics, 16(8), 441-458.

[35] Power,J.D., Cohen,A.L., Nelson,S.M., Wig,G.S., Barnes,K.A., Church,J.A., Vogel,A.C., Laumann,T.O., Miezin,F.M., Schlaggar,B.L. and Petersen,S.E. (2011) Functional Network Organization of the Human Brain. Neuron, 72, 665-678.

[36] Richiardi,J., Altmann,A., Milazzo,A.C., Chang,C., Chakravarty,M.M., Banaschewski,T., Barker,G.J., Bokde,A.L., Bromberg,U., Büchel,C. and Conrod,P. (2015) Correlated gene expression supports synchronous activity in brain networks. Science, 348, 1241-1244.

[37] Rosa,M.J., Portugal,L., Hahn,T., Fallgatter,A.J., Garrido,M.I., Shawe-Taylor,J. and MouraoMiranda,J. (2015) Sparse network-based models for patient classification using fMRI. Neurolmage, 105, 493-506.

[38] Scott,H. and Panin,V.M. (2014) The role of protein N-glycosylation in neural transmission. Glycobiology, 24(5), 407-417.

[39] Supekar,K., Menon,V., Rubin,D., Musen,M., and Greicius,M.D. (2008) Network analysis of intrinsic functional brain connectivity in Alzheimer's disease. PLoS Computational Biology, 4(6), e1000100.

[40] Urs,N.M., Peterson,S.M. and Caron,M.G. (2017) New concepts in dopamine D2 receptor biased signaling and implications for schizophrenia therapy. Biological Psychiatry, 81(1), 78-85. 
bioRxiv preprint doi: https $/ /$ doi org/10.1101/2020 05.15.099028; this version posted May 16,2020 . The copyright holder for this preprint

(which was not certified by peer review) is the author/funder, who has granted bioRxiv a license to display the preprint in perpetuity. It is made available under aCC-BY-NC-ND 4.0 International license.

[41] Wood,D., King,M., Landis,D., Courtney,W., Wang,R., Kelly,R., Turner,J.A. and Calhoun,V.D. (2014) Harnessing modern web application technology to create intuitive and efficient data visualization and sharing tools. Frontiers in Neuroinformatics, 8(71).

[42] Zeng,Y. and Breheny,P. (2016) Overlapping group logistic regression with applications to genetic pathway selection. Cancer Informatics, 15, CIN-S40043.

[43] Zhou,L., Wang,L. and Ogunbona,P. (2014) Discriminative sparse inverse covariance matrix: Application in brain functional network classification. In Proceedings of the IEEE Conference on Computer Vision and Pattern Recognition, 3097-3104. 
(a)
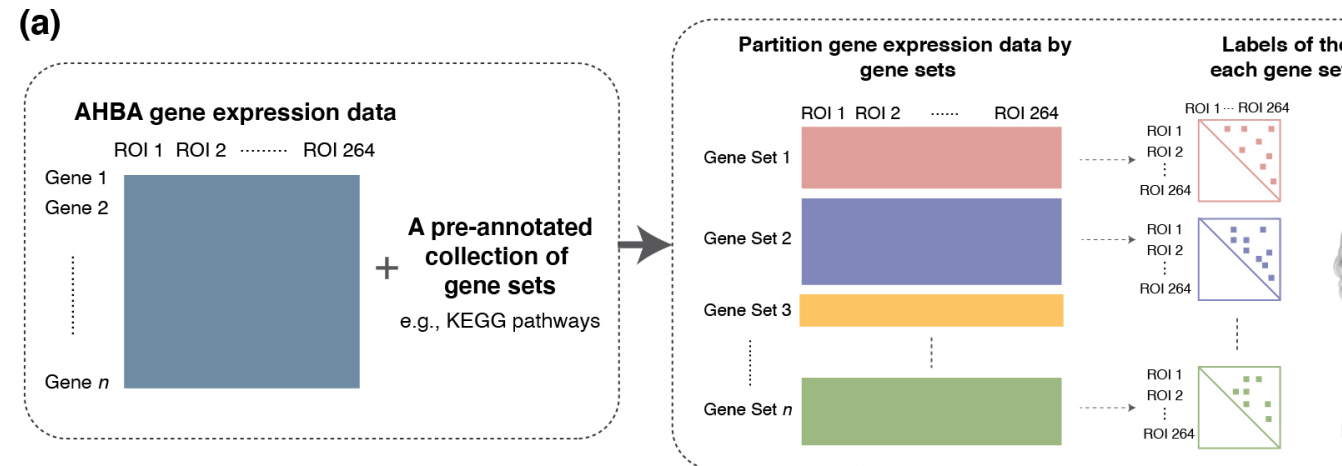
most informative edges of

(b)
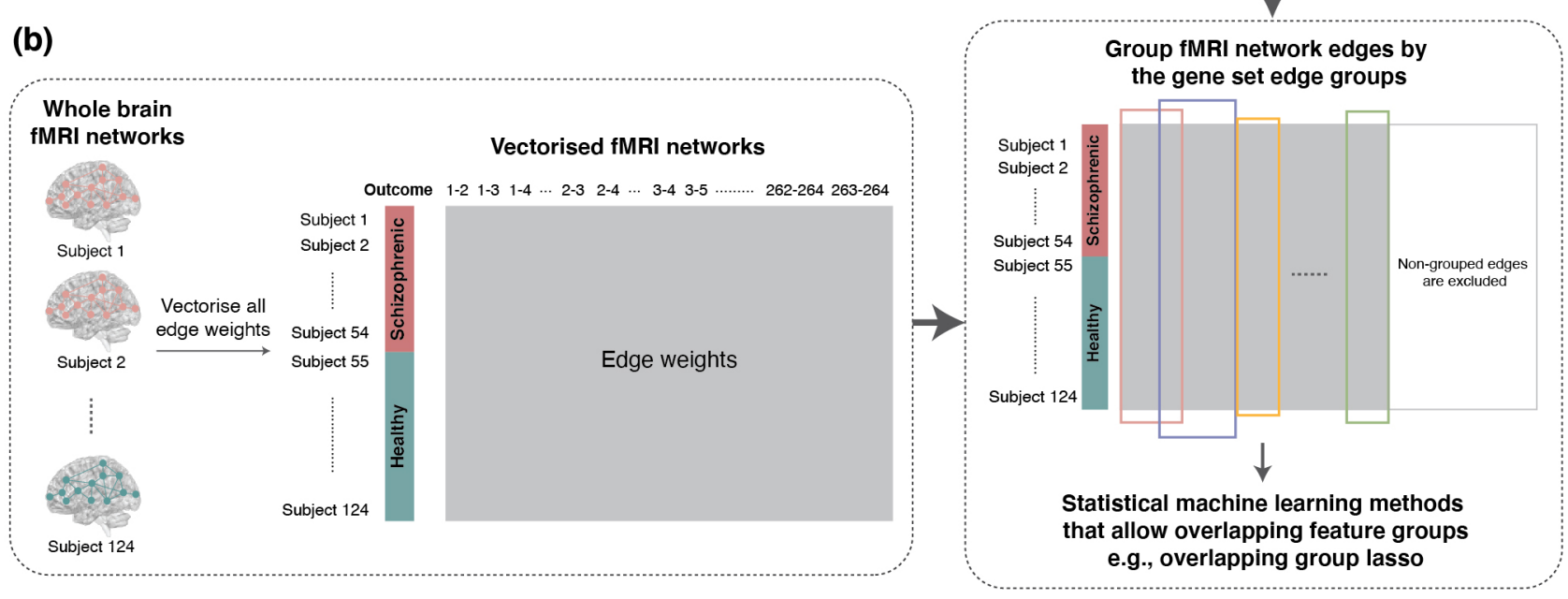

Figure 1: Schematic illustration of brainclass. (a) Construction of gene set edge groups based on transcriptional data. In the left panel, processed transcriptional data are represented as a data matrix with rows corresponding to genes and columns to ROls. Given a GSC of interest, the transcriptional data matrix is partitioned by each gene set, and the ROl-wise transcriptional network is calculated for each gene set. Labels of the most highly weighted edges in each gene set expression network form a gene set edge group, labelled by the name of the corresponding gene set. (b) fMRI network classification. Functional connectivity edge weights are used as the features, which are grouped according to the previously constructed gene set edge groups. (ROI: Region of interest; GSC: gene set collection. ) 
(a)

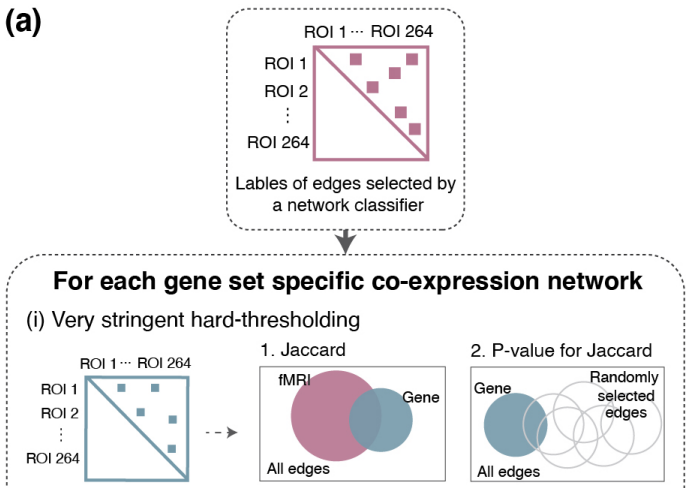

(ii) Less stringent hard-thresholding

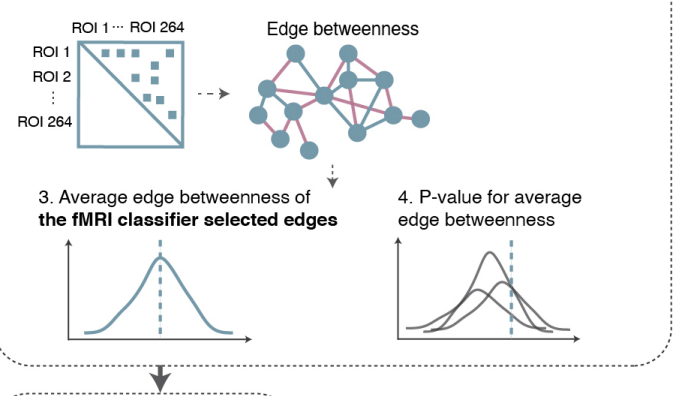

Gene set rankings by different gene sets

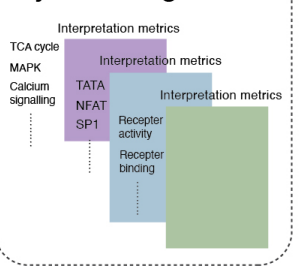

(b) Gene sets associated with schizophrenia by prior knowledge $\begin{array}{ccc}\text { Gene Set } 1 & \text { True assocation with } \\ \text { Gene Set } 2 & \rightarrow \text { the disease by DiGSeE }\end{array}$ Gene Set 3

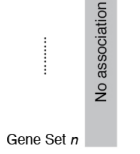

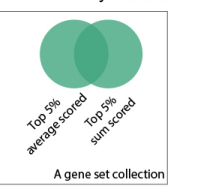

(c)

\begin{tabular}{|c|c|c|c|}
\hline Category & Collection & Number of gene sets & Median gene set size \\
\hline \multirow{2}{*}{ Curated } & KEGG & 151 & 15 \\
\cline { 2 - 4 } & REACTOME & 861 & 11 \\
\hline \multirow{2}{*}{ Motif } & Transcription factor targets & 606 & 77.5 \\
\hline \multirow{2}{*}{ Gene ontology } & Biological process & $4165^{\times}$ & 14 \\
\cline { 2 - 4 } & Cellular component & 511 & 20 \\
\cline { 2 - 4 } & Molecular function & 779 & 11 \\
\hline \multirow{2}{*}{ Immune } & Immunological signatures & 4872 & 54 \\
\hline \multirow{2}{*}{ Locational } & $\begin{array}{c}\text { Positional } \\
\text { (by chromosome) }\end{array}$ & 238 & 15 \\
\hline
\end{tabular}

(d)
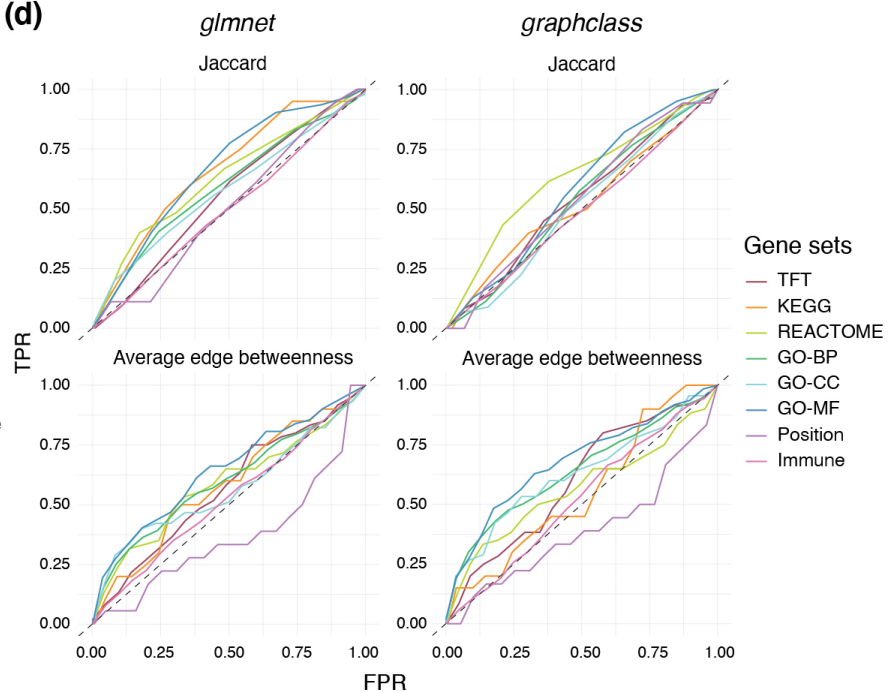

Figure 2: Post-hoc interpretation framework applied to existing fMRI network classification methods. (a) Schematic illustration of the post-hoc interpretation framework. (b) Gene sets with reported associations with schizophrenia in MEDLINE by DiGSeE. (c) Summary statistics on the pre-processed GSCs. Note: when evaluating the performance of the transcriptional-data-guided fMRI-network classifier with the GO GSC, we filtered to include only gene sets with size between 10 and 30 , resulting in 1,492 gene sets. (d) Receiver operating characteristic (ROC) curves for two post-hoc interpretation metrics versus constructed DiGSeE scores. (GSC: gene set collection; TPR: true positive rate; FPR: false positive rate; TFT: transcription factor target; GO: Gene Ontology; BP: biological process; CC: cellular component; MF: molecular function. ) 
(a)

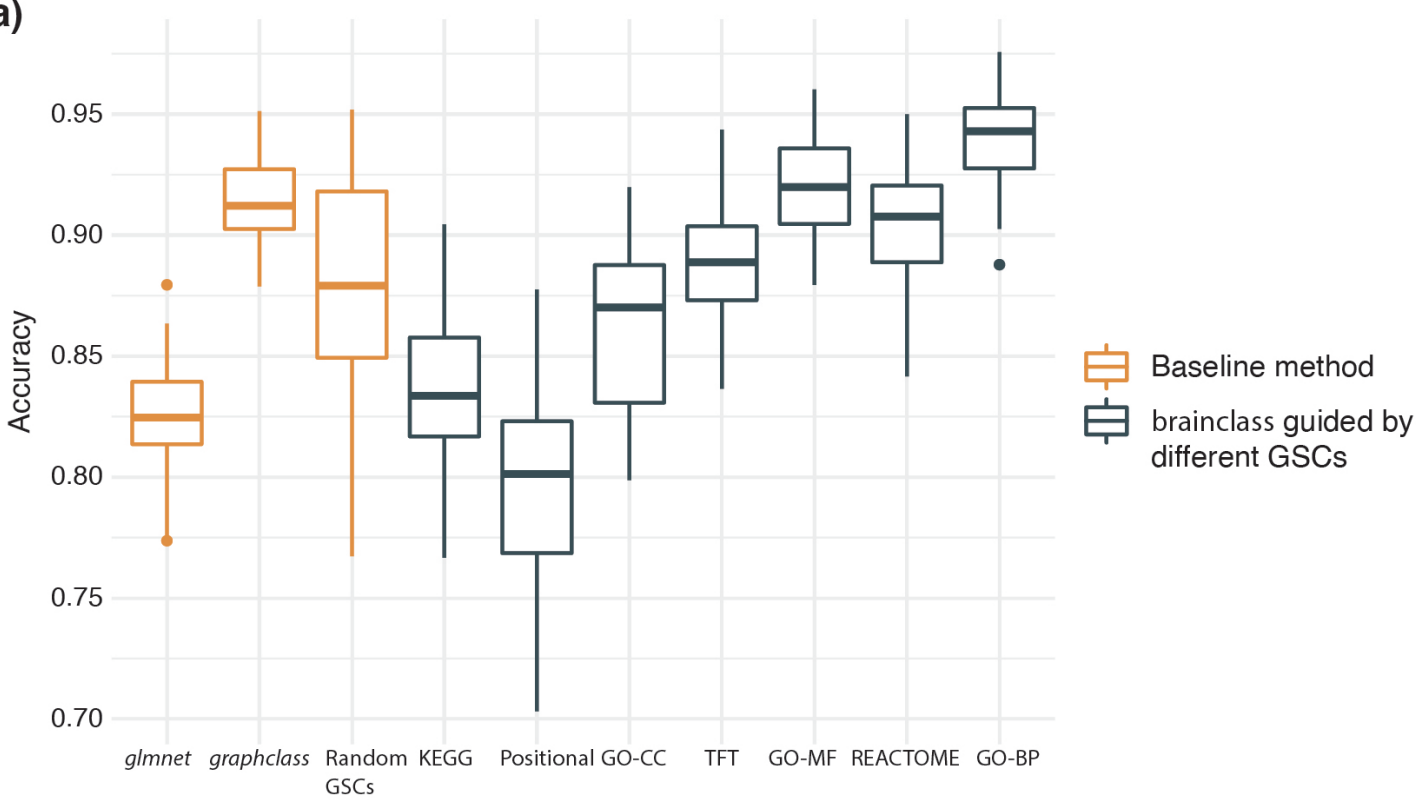

(b)



Figure 3: Evaluation of brainclass. (a) Prediction accuracy of the gene-expression guided fMRI network classification algorithm compared with baseline methods. We evaluated all fMRI network classifiers on the COBRE schizophrenia fMRI data in terms of the prediction accuracy in discriminating schizophrenic patients $(n=54)$ from healthy controls $(n=70)$ guided by different GSCs (obtained from MSigDB v7.0). Accuracy was calculated as the average prediction accuracy of 10 -fold cross-validations in 50 repeats. (b) Prediction accuracy of brainClass guided by the gene set information provided in versions v6.2 and v7.0 of MSigDB. 


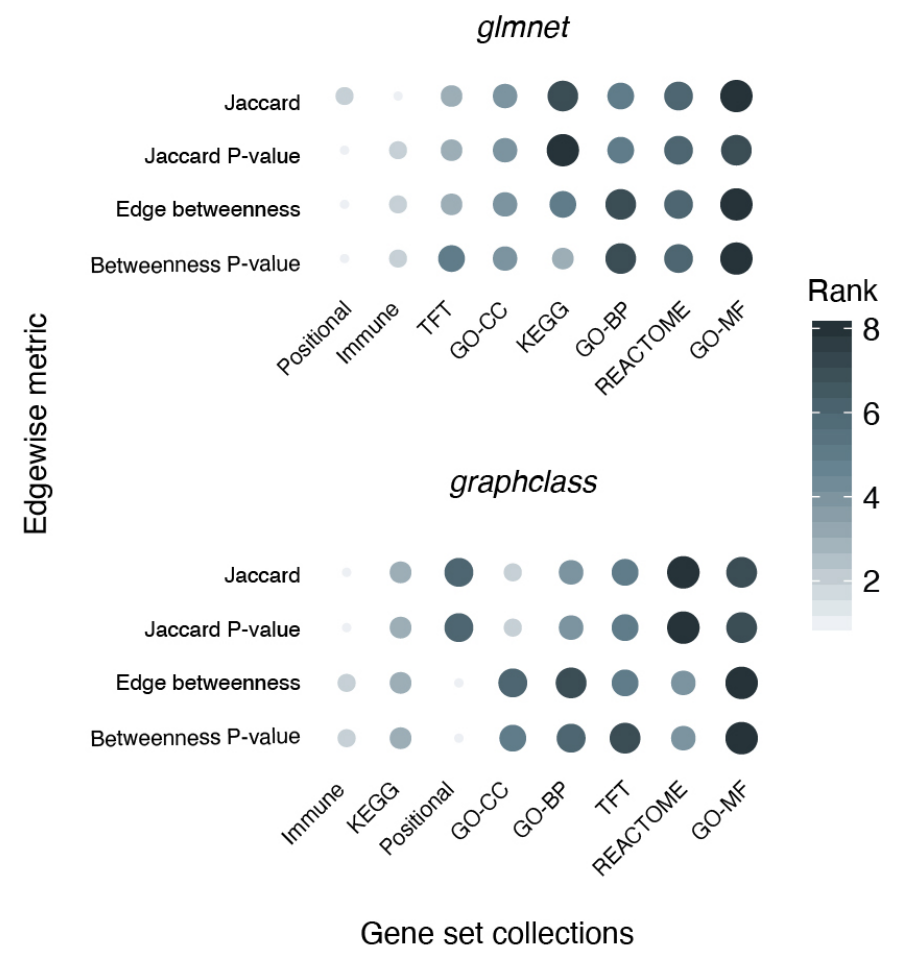

Figure 4: Interpretability of GSCs as measured by AUC in post-hoc interpretation framework for four different interpretation metrics (Jaccard, Jaccard $P$-value, Edge betweenness, and Edge betweenness $P$-value). ROC curves corresponding to each AUC value are depicted in Figure S7. Size and colour of the dots correspond to the rank of the GSC by AUC within each interpretation metric. For each classifier, GSCs on the horizontal axis are ordered by its average rank across all interpretation metrics. (AUC: area under the curve; ROC: receiver operating characteristic. ) 
Table 1: REACTOME pathways with a prioritisation score in top $5 \%$ in all ten folds in all 50 repeats of 10 -fold cross-validations, shown in alphabetical order together with the constructed DiGSeE gene set schizophrenia relevance scores of each pathway.

\begin{tabular}{|c|c|c|}
\hline Gene set & Sum score & Average score \\
\hline Adaptive Immune System & 7.04 & 0.04 \\
\hline Asparagine N-Linked Glycosylation & 2.59 & 0.04 \\
\hline Axon Guidance & 35.87 & 0.19 \\
\hline Cell Cell Communication & 3.74 & 0.07 \\
\hline Cell Cycle & 8.05 & 0.06 \\
\hline Cellular Responses to External Stimuli & 10.39 & 0.09 \\
\hline Cellular Responses to Stress & 9.06 & 0.09 \\
\hline Cytokine Signaling in Immune System & 54.84 & 0.26 \\
\hline Developmental Biology & 48.26 & 0.16 \\
\hline Disease & 56.25 & 0.22 \\
\hline Gene Expression Transcription & 35.95 & 0.13 \\
\hline Generic Transcription Pathway & 35.95 & 0.15 \\
\hline Hemostasis & 27.03 & 0.14 \\
\hline Innate Immune System & 38.95 & 0.15 \\
\hline Integration of Energy Metabolism & 7.29 & 0.19 \\
\hline Intracellular Signaling by Second Messengers & 26.41 & 0.31 \\
\hline MAPK Family Signaling Cascades & 31.12 & 0.34 \\
\hline Metabolism of Amino Acids and Derivatives & 21.20 & 0.21 \\
\hline Metabolism of Carbohydrates & 1.31 & 0.02 \\
\hline Metabolism of Lipids & 22.82 & 0.12 \\
\hline Metabolism of RNA & 1.04 & 0.01 \\
\hline Neuronal System & 73.54 & 0.40 \\
\hline Other Interleukin Signaling & 30.75 & 0.34 \\
\hline Phospholipid Metabolism & 3.83 & 0.06 \\
\hline Platelet Activation Signaling and Aggregation & 14.48 & 0.19 \\
\hline Post Translational Protein Modification & 25.90 & 0.08 \\
\hline Pyruvate Metabolism and Citric Acid TCA Cycle & 0.98 & 0.05 \\
\hline rRNA Processing & 0.00 & 0.00 \\
\hline rRNA Processing in the Nucleus and Cytosol & 0.00 & 0.00 \\
\hline Signaling by GPCR & 80.35 & 0.28 \\
\hline Signaling by Interleukins & 50.68 & 0.29 \\
\hline Signaling by Receptor Tyrosine Kinases & 56.88 & 0.34 \\
\hline Signaling by Rho GTPases & 6.95 & 0.05 \\
\hline Signaling by VEGF & 3.07 & 0.08 \\
\hline Signaling by WNT & 9.53 & 0.10 \\
\hline Transcriptional Regulation by TP53 & 4.83 & 0.08 \\
\hline Translation & 1.02 & 0.03 \\
\hline Transmission Across Chemical Synapses & 63.01 & 0.58 \\
\hline Transport of Small Molecules & 24.13 & 0.11 \\
\hline Vesicle Mediated Transport & 15.57 & 0.09 \\
\hline
\end{tabular}




\section{Supplementary methods and results for}

\section{Guiding and interpreting brain network classification with tran- scriptional data}

Mengbo $\mathrm{Li}^{1,2}$, Daniel Kessler ${ }^{3,4}$, Jesús Arroyo ${ }^{5}$, Saskia Freytag ${ }^{6,7}$, Melanie Bahlo ${ }^{6,7}$, Elizaveta Levina ${ }^{3}$ and Jean Yang ${ }^{1,2}$

${ }^{1}$ School of Mathematics and Statistics, Faculty of Science, the University of Sydney, NSW 2006, Australia

${ }^{2}$ Charles Perkins Centre, the University of Sydney, NSW 2006, Australia

${ }^{3}$ Department of Statistics, University of Michigan, Ann Arbor, MI 48109, USA

${ }^{4}$ Department of Psychiatry, University of Michigan, Ann Arbor, MI 48109, USA

${ }^{5}$ Center for Imaging Science, Johns Hopkins University, Baltimore, MD 21218, USA

${ }^{6}$ Population Health and Immunity Division, The Walter and Eliza Hall Institute of Medical Research, Parkville, VIC 3052, Australia

${ }^{7}$ Department of Medical Biology, University of Melbourne, Parkville, VIC 3052, Australia 


\section{Supplementary Methods}

\section{COBRE schizophrenia resting state fMRI data}

Functional MRI (fMRI) networks for subjects from the Center for Biomedical Research Excellence (COBRE) schizophrenia resting state $\mathrm{fMRI}$ data (54 schizophrenic and 70 healthy control) $[1,8]$ were downloaded from the supplement to [2]. Details on the pre-processing of raw anatomic and functional scans from the COBRE data set are provided in [2].

\section{Allen Human Brain Atlas (AHBA) whole human brain gene expression microarray data}

Brain-wide microarray gene expression data were obtained from the Allen Human Brain Atlas (AHBA) [4], which provides an anatomically comprehensive adult human brain transcriptome atlas comprising 3,702 spatially distinct brain tissue samples obtained from six cadaver brains profiled for more than 20, 000 genes. During pre-processing, each sample was assessed for its quality and samples with poor quality spot plots, unusual plots of log-intensity ratios versus log-intensity averages or abnormal gene expression distributions were excluded, leaving 3,546 samples. After pre-processing, the data were normalised using a conventional background correction in combination with quantile normalisation. Critically, all brain tissue samples were anatomically annotated to the normalised Montreal Neurological Institute (MNI) brain space (MNI152 non-linear). The MNI coordinates of each AHBA brain tissue sample were downloaded from https://github.com/chrisgorgo/alleninf/tree/master/alleninf/data.

\section{Power Brain Parcellation}

Power et al. (2011) proposed a functional brain parcellation consisting of 264 anatomically distinct regions of interest (ROls) comprising 14 functional brain systems modelled as $5 \mathrm{~mm}$ radius spheres (Figure S1a) [7], whose centre coordinates were also mapped to the MNI152 1mm brain space. ROls identified by the Power Parcellation were used as nodes to construct brain-wide fMRI networks and the gene set expression networks. In our analysis, pre-processed time series courses were extracted from voxels constituting each Power ROI from COBRE data, where node 75 is missing. The assignment of AHBA gene expression samples via sample MNI coordinates to the Power ROls is described in the next section.

\section{Brain regional mapping of AHBA mircroarray samples to Power Parcellation ROls}

ROIs identified by the Power Parcellation [7] were used to construct gene set expression networks. To obtain gene expression profiles for each Power ROI, AHBA microarray samples were spatially mapped to the ROls via their MNI coordinates. In order to obtain gene expression profiles for as many Power ROls as possible, we enlarged the radius of spheres defined by the Power Parcellation to get enlarged ROls for better coverage. The brain regional mapping from AHBA samples to (enlarged) Power ROls has 3 steps (Figure S3):

Step 1 Map the AHBA sample to a Power ROI if it lies within the $5 \mathrm{~mm}$ radius from the centre of the $\mathrm{ROI}$ according to the original definition. Out of the 3,546 preprocessed AHBA brain tissue samples, 240 samples got assigned to 118 ROls.

Step 2 Enlarge the radius of spheres defined as ROls by the Power Parcellation [7]. While keeping the centre MRI coordinates of each sphere unchanged, we increase the radius of all spheres from $5 \mathrm{~mm}$ to $12 \mathrm{~mm}$. Some ROls become overlapped when $r=12 \mathrm{~mm}$. Note that samples can only be mapped into the non-overlapping regions of each $\mathrm{ROI}$ in this step. The enlarged radius of $12 \mathrm{~mm}$ was picked so that as many AHBA samples were mapped to the non-overlapped regions as possible (Figure S2). 1, 129 gene 
expression samples were mapped to 196 different enlarged ROls in this step. So far, 1,369 AHBA samples were mapped to 211 enlarged ROls.

Step 3 Map the remaining AHBA gene expression samples to the so-far empty enlarged ROls $(r=$ $12 \mathrm{~mm}$ ). In this step, 119 samples were mapped to 52 enlarged ROls.

Eventually after all three steps, 1,488 AHBA microarray samples were mapped into 248 enlarged Power ROls.

\section{Dimension reduction on the AHBA microarray data}

After the initial data pre-processing and normalisation on the AHBA gene expression data, we obtained a $3,546 \times 32,488$ data matrix, where each row corresponds to an AHBA brain tissue sample and each column corresponds to a probe ID. We first filtered out probes that were not annotated to any HGNC gene symbols and tissue samples that were not assigned to any ROI. This returned us a sample ID by gene symbol data matrix $(1,488 \times 19,227)$. We discarded ROI75 as it is missing in COBRE data. For each gene, we calculated its average expression level in samples assigned to the same Power ROI to obtain a ROI by gene symbol data matrix $(247 \times 19,227)$. We further filtered out genes with low expression in all ROls. Average gene expression levels across 247 ROls for each of the 19,227 genes were calculated and those below the 3rd quartile were filtered out. We ended up with a $247 \times 4,807 \mathrm{ROI}$ by gene symbol data matrix, where each entry in the matrix contains the average expression level of a gene within the enlarged Power ROI (Figure S1b).

\section{Molecular Signatures Database (MSigDB, v7.0)}

Gene set collections from the Molecular Signatures Database (MSigDB, v7.0) are publicly available at $\mathrm{http}: / /$ software.broadinstitute.org/gsea/msigdb/index.jsp, which is a comprehensive gene set database that is commonly used to perform gene set enrichment analysis (GSEA), providing labelled gene set information on biological processes and disease pathways to enable biologically meaningful interpretation of transcriptional data [6]. Typically, each category of gene set collections represent a particular domain of knowledge [6] . For instance, gene ontology (GO) [3] gene sets are derived based on hierarchically controlled GO terms including molecular function (MF), cellular component (CC) or biological process (BP) to provide meaningful annotations for gene functions and products. Alternatively, gene sets can also be curated simply by the physical location of each gene on the chromosomes (the positional gene set collection). MSigDB also provides processed and annotated gene sets that constitute various types of biological pathways such as KEGG or REACTOME.

\section{Gene set schizophrenia association scores based on DiGSeE}

Disease gene search engine with evidence sentences (DiGSeE) [5] is a web tool for gene-disease association queries (http://gcancer.org/digsee). The database searches for genes associated with the disease of interest (e.g. schizophrenia) in current literature, and provides a score for each gene, based on joint occurrences of the disease and relevant genes through biological events in MEDLINE abstracts. Geneschizophrenia association scores were obtained from DiGSeE for our case study. To account for different aliases of the same gene, we summed association scores for gene symbols mapped to the same entrez ID. A natural log-transformation was applied to raw scores due to its right-skewed distribution. We then filtered out genes with a relatively low schizophrenia association score by keeping only genes scored higher than or equal to the median of log-transformed scores.

After pre-processing, we constructed two types of schizophrenia relevance scores for each gene set: DiGSeE sum score and DiGSeE average score. We first filtered each gene set by removing genes previously identified as having low expression in gene expression data and discarded gene sets consisting of 
bioRxiv preprint doi: https://doi.org/10.1101/2020.05.15.099028; this version posted May 16,2020. The copyright holder for this preprint (which was not certified by peer review) is the author/funder, who has granted bioRxiv a license to display the preprint in perpetuity. It is made available under aCC-BY-NC-ND 4.0 International license.

less than 5 genes post filtering. Gene set schizophrenia relevance scores were calculated by taking the sum and the average of gene-schizophrenia association scores with genes from each filtered gene set (Figure S1c).

\section{Receiver operating characteristic (ROC) curve and area under the curve (AUC)}

Within each gene set collection (GSC), gene sets were ranked by post-hoc interpretability metrics. True positives (gene sets associated with schizophrenia) and true negatives were defined by summarised gene set schizophrenia relevance scores based on DiGSeE. By each interpretability metric, gene sets that are ranked top $x$ percent (from $0 \%$ to $100 \%$ at a step of $5 \%$ ) were categorised as test positives (associated with schizophrenia) and test negatives (not associated with schizophrenia) otherwise. The accuracy of gene set categorisation by each metric was evaluated by the area under the receiver operating characteristic (ROC) curve, where the true positive rate is plotted against the false positive rate by comparing true positives with test positives. Complete results are provided in Figure S7, with AUC for each curve in the figure provided in Table S6 and Table S7. 


\section{Supplementary Results}

\section{Gene set prioritisation results when guided by different collections of gene sets}

Given selected functional edge features by the classifier, a gene set prioritisation metric was calculated as described in the Methods section. Gene sets were then ranked within each GSC by the prioritisation metric. Gene sets ranked top $5 \%$ within each GSC in all ten folds of all 50 repetitons of 10 -fold cross-validations are provided in Tables S1 to S5. For each GSC, distributions of gene set schizophrenia relevance scores for (i) all gene sets in each GSC and (ii) the prioritised gene sets are provided in Figure S4.

\section{Number of selected features when guided by different GSCs}

Given a particular GSC, we observed that the distribution of the number of selected features (around $10 \%$ of all included features are selected) and the prediction accuracy are robust to the regularisation parameter $\lambda$ in grpregOverlap, when $1 \times 10^{-3} \leq \lambda<1 \times 10^{-2}$. In our implementation, the default is $\lambda=5 \times$ $10^{-3}$. The number of features included in classification when guided by different GSCs, and the median number of selected features (that had non-zero coefficients) in 10-fold cross-validations over 50 repeats are summarised in Figure S5. 


\section{References}

[1] Aine,C.J., Bockholt,H.J., Bustillo,J.R., CaÃśive,J.M., Caprihan,A., Gasparovic,C., Hanlon,F.M., Houck,J.M., Jung,R.E., Lauriello,J. and Liu,J. (2017) Multimodal neuroimaging in schizophrenia: description and dissemination. Neuroinformatics, 15(4), 343-364.

[2] Arroyo Relión,J.D., Kessler,D., Levina,E., and Taylor,S.F. (2019) Network classification with applications to brain connectomics. The Annals of Applied Statistics, 13(3), 1648-1677.

[3] Ashburner,M., Ball,C.A., Blake,J.A., Botstein,D., Butler,H., Cherry,J.M., Davis,A.P., Dolinski,K., Dwight,S.S., Eppig,J.T. and Harris,M.A. (2000) Gene Ontology: tool for the unification of biology. Nature genetics, 25(1), 25-29.

[4] Hawrylycz,M.J., Lein,E.S., Guillozet-Bongaarts,A.L., Shen,E.H., Ng,L., Miller,J.A., Van De Lagemaat,L.N., Smith,K.A., Ebbert,A., Riley,Z.L. and Abajian,C. (2012) An anatomically comprehensive atlas of the adult human brain transcriptome. Nature, 489, 391-399.

[5] Kim,J., So,S., Lee,H.J., Park,J., Kim,J.J. and Lee,H. (2013) DigSee: Disease gene search engine with evidence sentences (version cancer). Nucleic Acid Res., 41, 510-517.

[6] Liberzon,A., Subramanian,A., Pinchback,R., ThorvaldsdÃşttir,H., Tamayo,P. and Mesirov,J.P. (2011) Molecular signatures database (MSigDB) 3.0. Bioinformatics, 27(12), 1739-1740.

[7] Power,J.D., Cohen,A.L., Nelson,S.M., Wig,G.S., Barnes,K.A., Church,J.A., Vogel,A.C., Laumann,T.O., Miezin,F.M., Schlaggar,B.L. and Petersen,S.E. (2011) Functional Network Organization of the Human Brain. Neuron, 72, 665-678.

[8] Wood,D., King,M., Landis,D., Courtney,W., Wang,R., Kelly,R., Turner,J.A. and Calhoun,V.D. (2014) Harnessing modern web application technology to create intuitive and efficient data visualization and sharing tools. Frontiers in Neuroinformatics, 8(71).

[9] Xia,M., Wang,J. and He,Y. (2013) BrainNet Viewer: a network visualization tool for human brain connectomics. PloS one, 8(7), e68910. 


\section{Supplementary Figures}

(a)

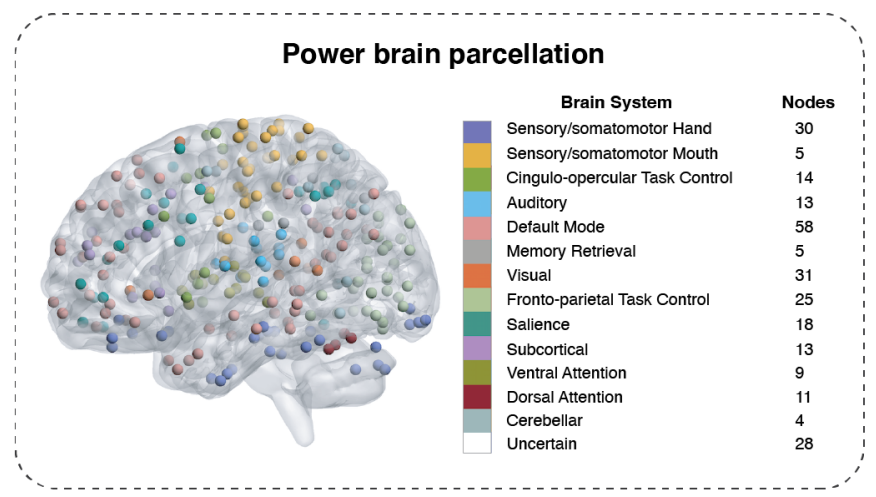

(c)

DiGSeE gene set schizophrenia relevance scores

Step 1: Filter for genes scored with high confidence

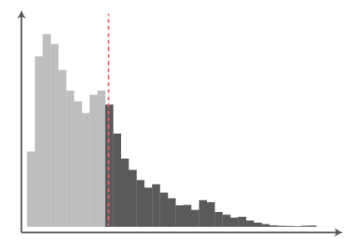

Step 2: Create a disease score of each gene set

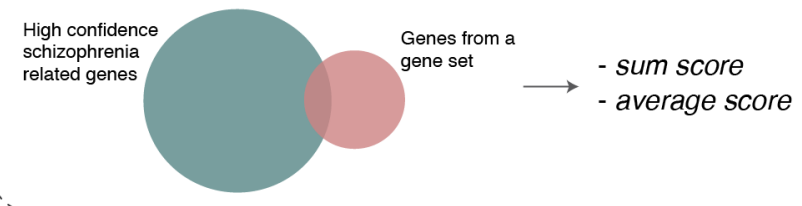

(b)

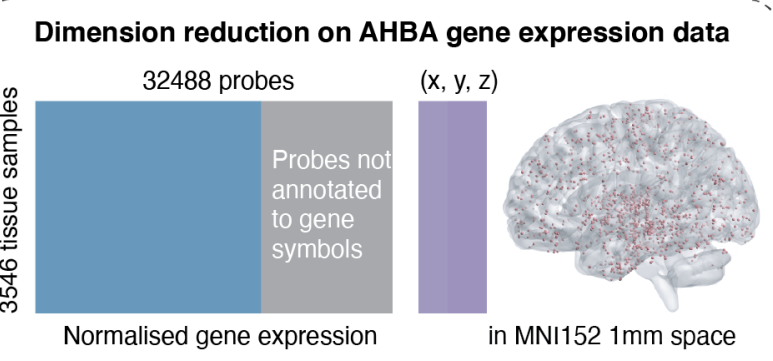
in MNI152 1mm space
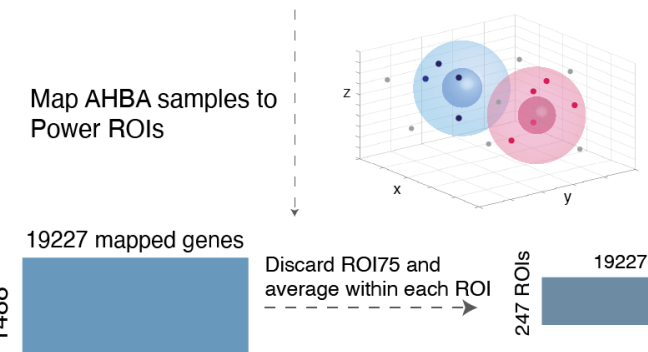

Discard ROI75 and average within each ROI

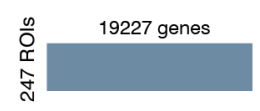

Filter out lowly expressed genes

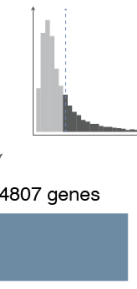

Downsized AHBA gene expression data

Figure S1: Data pre-processing. (a) The Power brain parcellation. Regions of interest (ROIs) are modelled as $5 \mathrm{~mm}$ radius spheres and coloured by functional brain systems. The total number of ROls in each system are also indicated. This illustration was created using the BrainNet Viewer Matlab software [9]. (b) Dimension reduction on the Allen Human Brain Atlas (AHBA) gene expression data. (c) Construction of schizophrenia relevance scores for each gene set based on the gene-disease association query results from DiGSeE. 
bioRxiv preprint doi: https://doi.org/10.1101/2020.05.15.099028; this version posted May 16, 2020. The copyright holder for this preprint (which was not certified by peer review) is the author/funder, who has granted bioRxiv a license to display the preprint in perpetuity. It is made available under aCC-BY-NC-ND 4.0 International license.

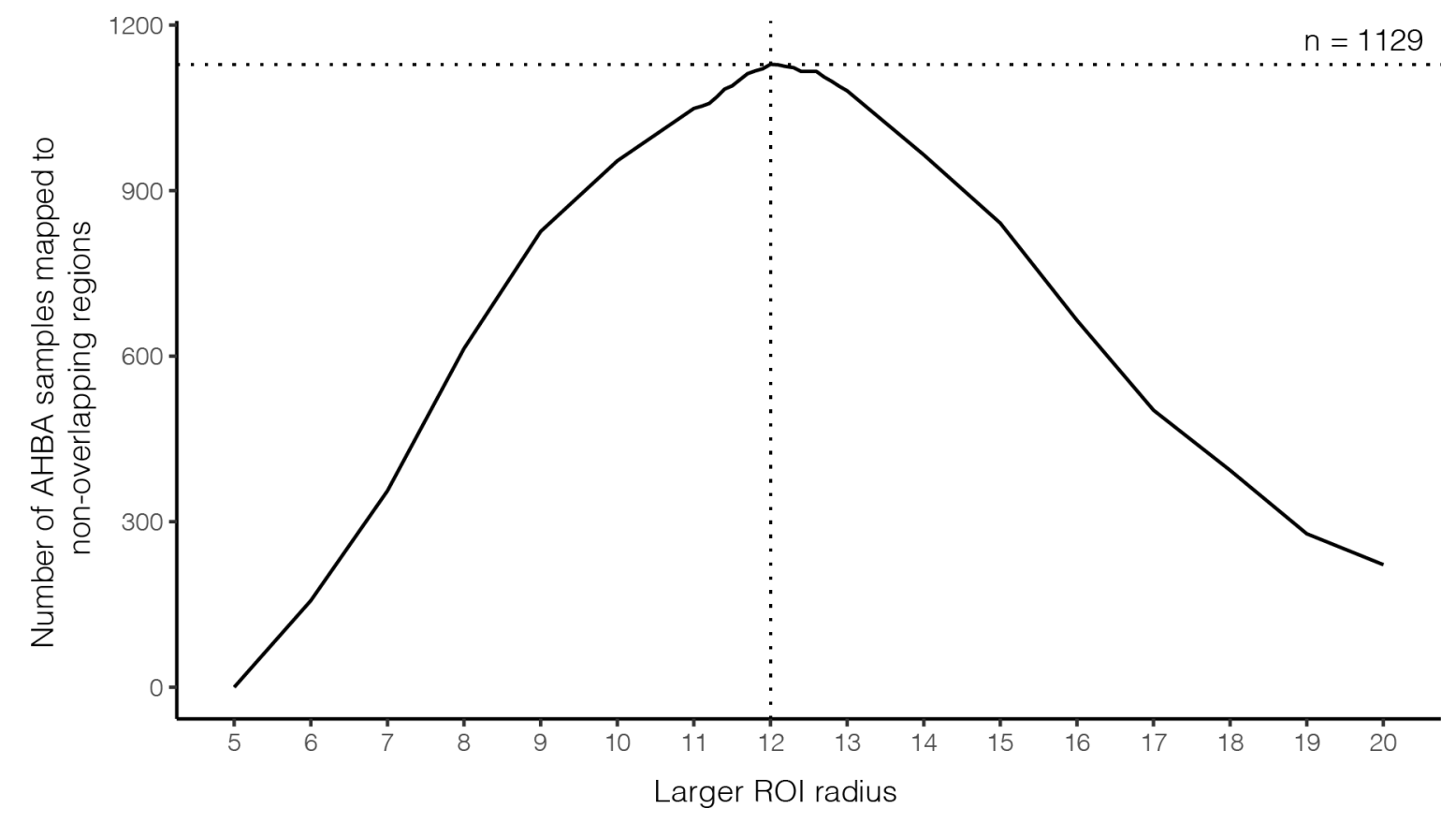

Figure S2: Number of AHBA samples mapped to the non-overlapping regions of enlarged ROls as we increase the radius of Power ROI spheres. Originally, Power ROls are modelled as $r=5 \mathrm{~mm}$ spheres, and none of them overlap. In order to obtain gene expression profiles for as many ROIs as possible, we increased the radius of all spheres at a step of $0.01 \mathrm{~mm}$, from $5 \mathrm{~mm}$ to $20 \mathrm{~mm}$. As the radius of all ROls increase, some of them start to overlap, and we only map the AHBA samples located in the non-overlapping regions to its closest $\mathrm{ROI}$. 
bioRxiv preprint doi: https://doi.org/10.1101/2020.05.15.099028; this version posted May 16, 2020. The copyright holder for this preprint (which was not certified by peer review) is the author/funder, who has granted bioRxiv a license to display the preprint in perpetuity. It is made available under aCC-BY-NC-ND 4.0 International license.

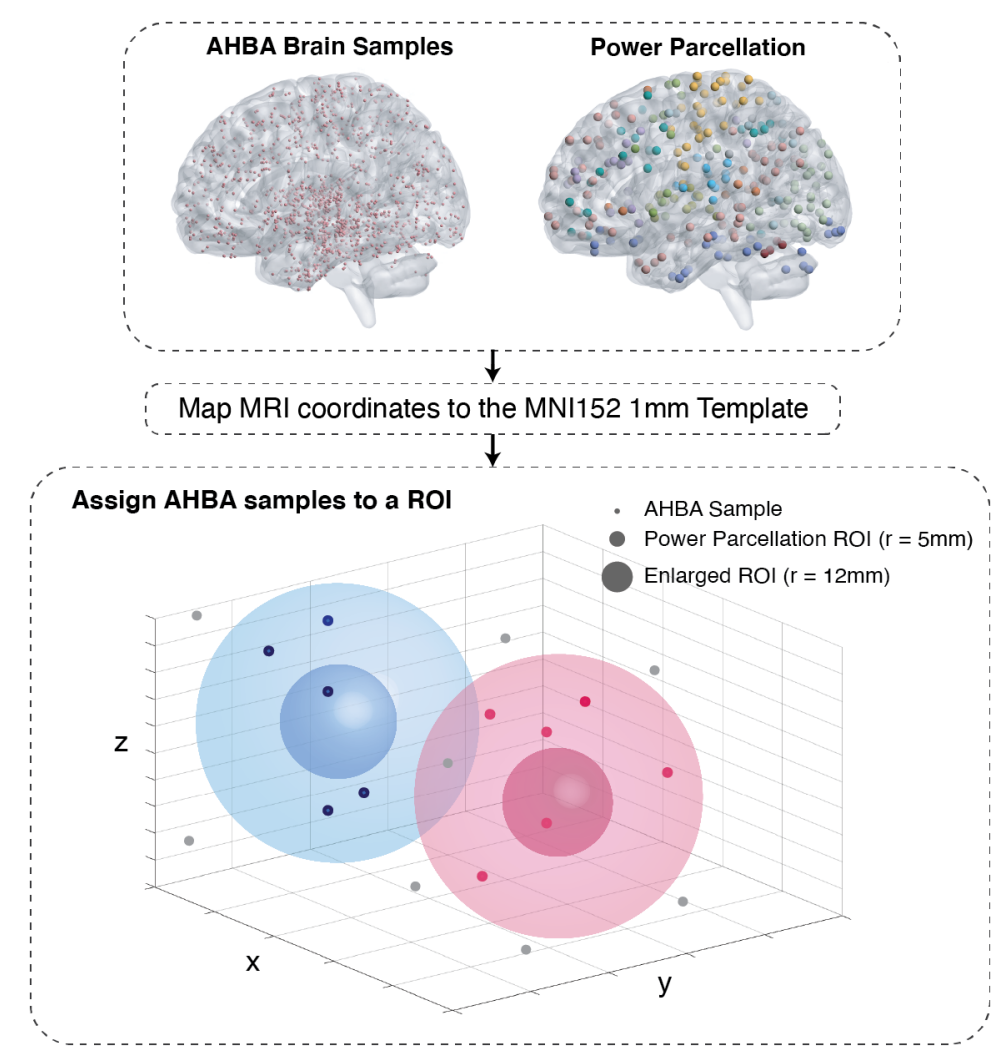

Figure S3: Schematic illustration of the AHBA microarray sample assignment to the Power brain parcellation. 
bioRxiv preprint doi: https://doi org/10.1101/2020 05.15.099028; this version posted May 16, 2020. The copyright holder for this preprint (which was not certified by peer review) is the author/funder, who has granted bioRxiv a license to display the preprint in perpetuity. It is made available under aCC-BY-NC-ND 4.0 International license.
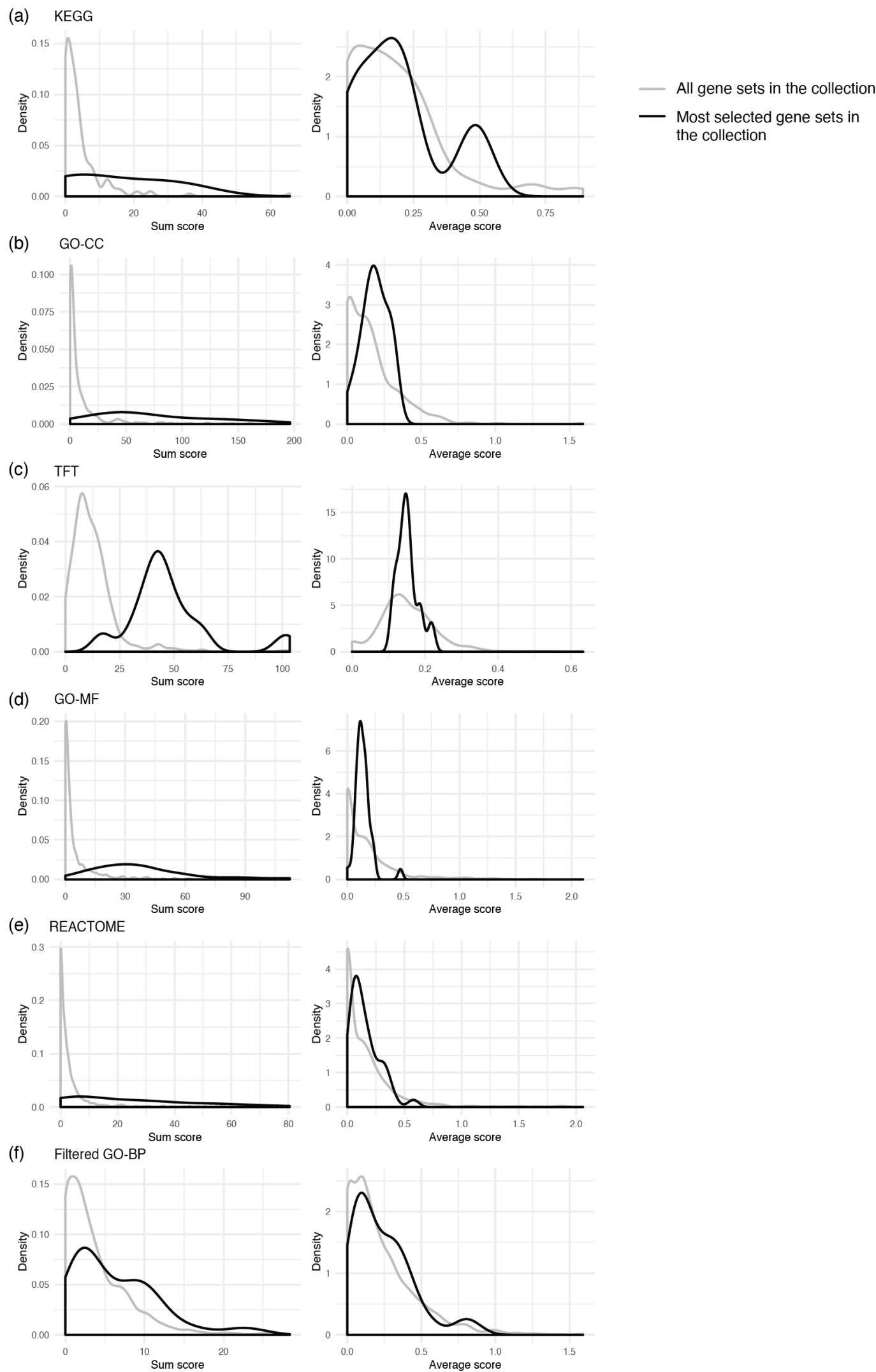

Figure S4: Gene set schizophrenia association score distributions. All gene set collections were filtered and processed as described in the Supplementary Methods section. Distributions of all gene set schizophrenia relevance scores are plotted in grey. Plotted in black are the distributions of the gene set association scores for those selected in all 50 repeats of 10 -fold cross-validations in the case study. The filtered GO biological process (BP) term collection was obtained by only keeping those sized between 10 and 30. (Abbreviations: TFT: transcription factor target; CC: cellular component; MF: molecular function. ) 
bioRxiv preprint doi: https://doi org/10.1101/2020 05.15.099028: this version posted May 16,2020 . The copyriaht holder for this preprint (which was not certified by peer review) is the author/funder, who has granted bioRxiv a license to display the preprint in perpetuity. It is made available under aCC-BY-NC-ND 4.0 International license.

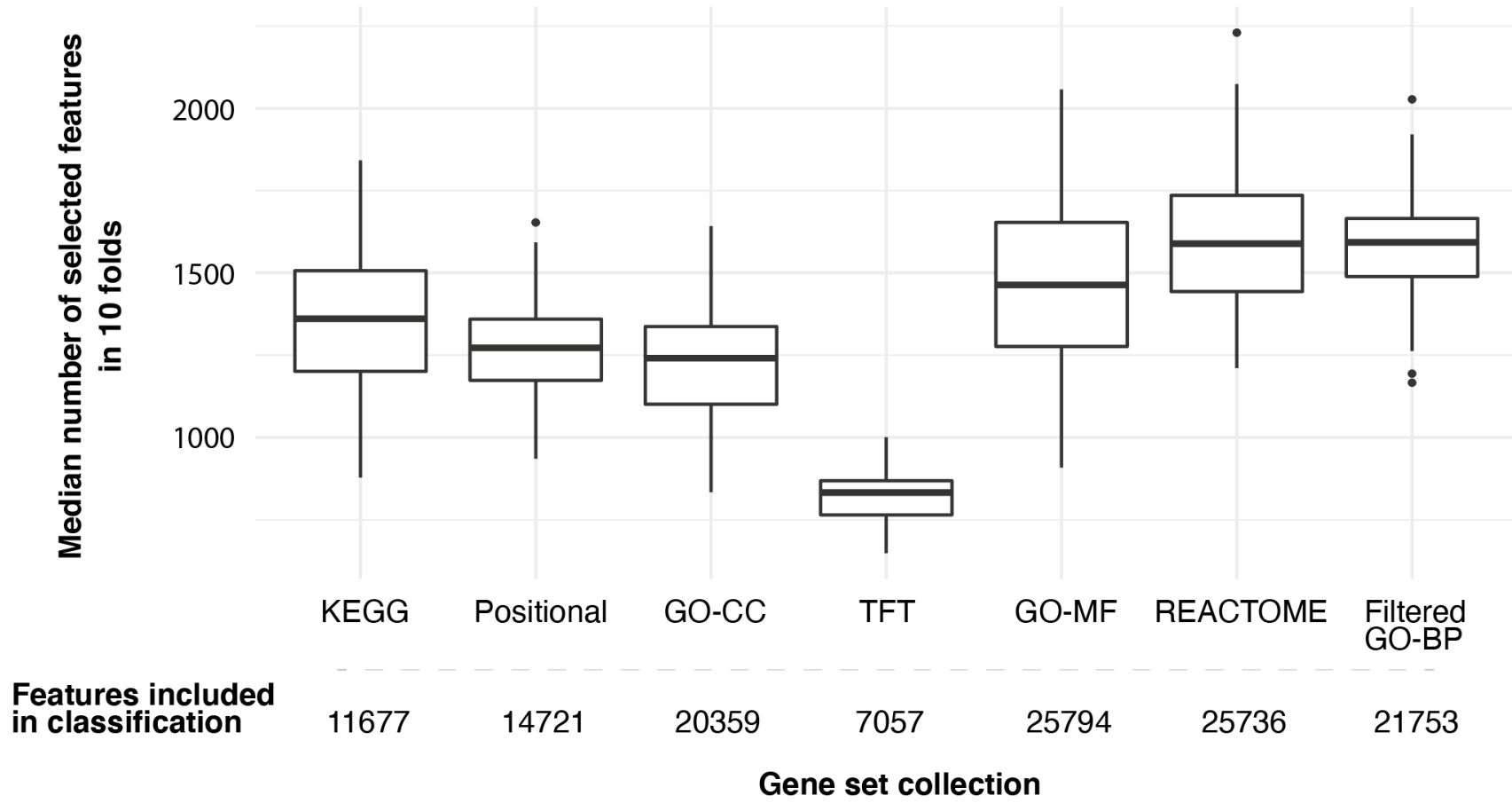

Figure S5: Median number of selected features in 10-fold cross-validations over 50 trials by the gene expression guided classification algorithm $\left(\lambda=5 \times 10^{-3}\right)$. By design, edges that do not belong to any gene set edge groups are excluded from model training, thus the selection of GSC directly determines which features are included in classification. The numbers of features included in model training are provided.

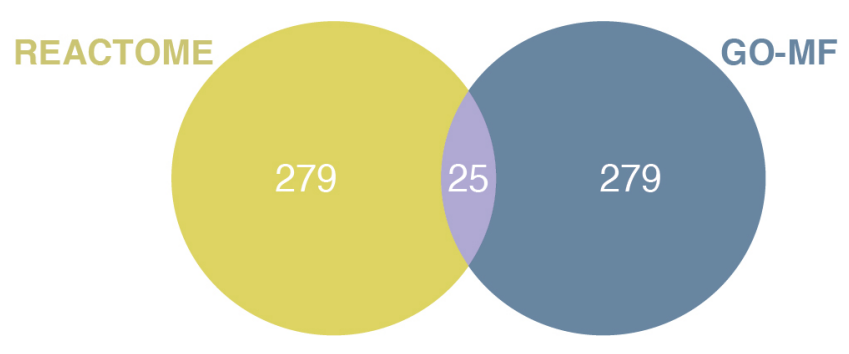

Figure S6: The overlap between most selected functional edges when the proposed classifier was guided by REACTOME pathways versus the gene ontology (GO) molecular function (MF) terms. Most selected edges were edges selected in all 10 folds and all 50 trials of cross-validations. 
bioRxiv preprint doi: https://doi.org/10.1101/2020 05.15.099028; this version posted May 16, 2020. The copyright holder for this preprint (which was not certified by peer review) is the author/funder, who has granted bioRxiv a license to display the preprint in perpetuity. It is made available under aCC-BY-NC-ND 4.0 International license.

(a) Edge selection by cross-validation using glmnet

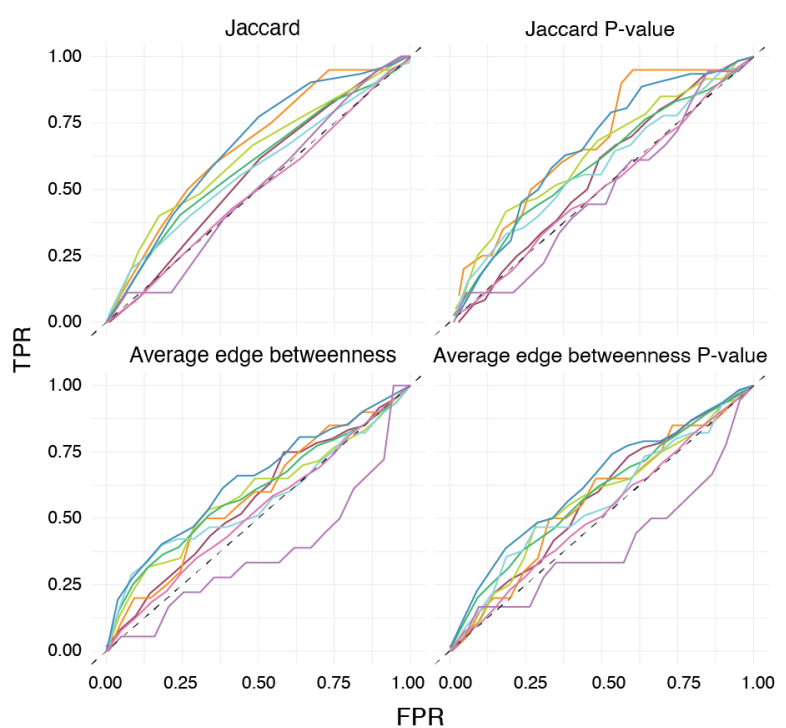

(b) Edge selection by cross-validation using graphclass

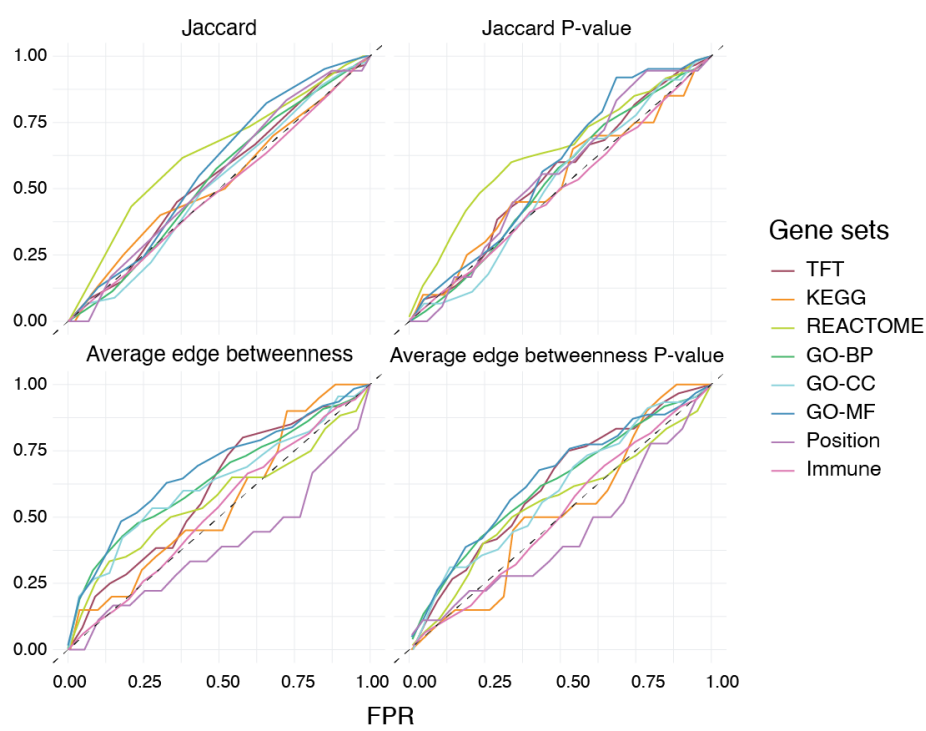

Figure S7: Receiver operating characteristic (ROC) curve evaluation of each post-hoc interpretability metric when different GSCs were used for interpreting predictive functional edges selected by (a) glmnet and (b) graphclass. (FPR: false positive rate; TPR: true positive rate. ) 
bioRxiv preprint doi: https://doi.org/10.1101/2020 05.15.099028: this version posted May 16. 2020. The copyriaht holder for this preprin (which was not certified by peer review) is the author/funder, who has granted bioRxiv a license to display the preprint in perpetuity. It is made available under aCC-BY-NC-ND 4.0 International license.

\section{Supplementary Tables}

Table S1: KEGG pathway gene sets with a prioritisation score in top 5\% in all ten folds in all 50 repeats of 10 -fold cross-validations in alphabetical order.

\begin{tabular}{lrr}
\hline Gene set & Sum score & Average score \\
\hline Calcium Signaling Pathway & 36.32 & 0.48 \\
Citrate Cycle TCA Cycle & 0.00 & 0.00 \\
Glycolysis Gluconeogenesis & 0.96 & 0.09 \\
Pathways in Cancer & 25.22 & 0.23 \\
Regulation of Actin Cytoskeleton & 12.18 & 0.17 \\
\hline
\end{tabular}

Table S2: Transcription factor target gene sets with a prioritisation score in top $5 \%$ in all ten folds in all 50 repeats of 10 -fold cross-validations in alphabetical order.

\begin{tabular}{lrr}
\hline Gene set & Sum score & Average score \\
\hline AAANWWTGC_UNKNOWN & 16.69 & 0.19 \\
AAAYRNCTG_UNKNOWN & 28.68 & 0.22 \\
AACTTT_UNKNOWN & 103.36 & 0.14 \\
CACGTG_MYC_Q2 & 41.78 & 0.14 \\
CAGCTG_AP4_Q5 & 58.25 & 0.11 \\
CAGGTA_AREB6_01 & 42.10 & 0.15 \\
CTGCAGY_UNKNOWN & 63.28 & 0.22 \\
CTTTAAR_UNKNOWN & 48.13 & 0.14 \\
CTTTGA_LEF1_Q2 & 54.82 & 0.14 \\
GATTGGY_NFY_Q6_01 & 37.46 & 0.12 \\
GCANCTGNY_MYOD_Q6 & 51.12 & 0.15 \\
GGGTGGRR_PAX4_03 & 51.60 & 0.12 \\
RNGTGGGC_UNKNOWN & 43.77 & 0.15 \\
RTAAACA_FREAC2_01 & 39.18 & 0.12 \\
RYTTCCTG_ETS2_B & 43.62 & 0.13 \\
TAATTA_CHX10_01 & 43.57 & 0.14 \\
TATAAA_TATA_01 & 63.05 & 0.16 \\
TCANNTGAY_SREBP1_01 & 17.32 & 0.12 \\
TGACAGNY_MEIS1_01 & 42.53 & 0.15 \\
TGACATY_UNKNOWN & 36.29 & 0.15 \\
TGACCTY_ERR1_Q2 & 47.17 & 0.13 \\
TGCCAAR_NF1_Q6 & 45.08 & 0.17 \\
TGGAAA_NFAT_Q4_01 & 99.81 & 0.16 \\
TGTTTGY_HNF3_Q6 & 40.36 & 0.16 \\
WGTTNNNNNAAA_UNKNOWN & 33.75 & 0.19 \\
WTTGKCTG_UNKNOWN & 33.38 & 0.19 \\
\hline
\end{tabular}


bioRxiv preprint doi: https://doi org/10.1101/2020 05.15.099028; this version posted May 16, 2020. The copyright holder for this preprint (which was not certified by peer review) is the author/funder, who has granted bioRxiv a license to display the preprint in perpetuity. It is made available under aCC-BY-NC-ND 4.0 International license.

Table S3: Gene ontology cellular component gene sets with a prioritisation score in top $5 \%$ in all ten folds in all 50 repeats of 10 -fold cross-validations in alphabetical order.

\begin{tabular}{lrr}
\hline Gene set & Sum score & Average score \\
\hline Axon & 82.88 & 0.32 \\
Catalytic Complex & 9.51 & 0.04 \\
Cell Body & 51.17 & 0.23 \\
Cell Junction & 89.17 & 0.17 \\
Cell Projection Part & 123.33 & 0.24 \\
Cytoskeletal Part & 40.62 & 0.09 \\
Endoplasmic Reticulum & 66.17 & 0.13 \\
Envelope & 37.04 & 0.15 \\
Filopodium & 9.84 & 0.20 \\
Golgi Apparatus & 42.91 & 0.10 \\
Golgi Apparatus Part & 20.93 & 0.08 \\
Intrinsic Component of Plasma Membrane & 137.94 & 0.25 \\
Membrane Protein Complex & 60.51 & 0.20 \\
Mitochondrion & 46.46 & 0.14 \\
Neuron Part & 196.16 & 0.28 \\
Neuron Projection & 159.93 & 0.31 \\
Nuclear Chromosome Telomeric Region & 0.00 & 0.00 \\
Perinuclear Region of Cytoplasm & 45.77 & 0.19 \\
Plasma Membrane Region & 121.90 & 0.27 \\
Somatodendritic Compartment & 107.55 & 0.31 \\
Supramolecular Complex & 39.87 & 0.15 \\
Synapse & 161.38 & 0.31 \\
Vesicle Membrane & 46.68 & 0.20 \\
Whole Membrane & 79.23 & 0.16 \\
\hline
\end{tabular}


bioRxiv preprint doi: https://doi.org/10.1101/2020.05.15.099028: this version posted Mav 16. 2020. The copyriaht holder for this preprin (which was not certified by peer review) is the author/funder, who has granted bioRxiv a license to display the preprint in perpetuity. It is made available under aCC-BY-NC-ND 4.0 International license.

Table S4: Gene ontology molecular function gene sets with a prioritisation score in top $5 \%$ in all ten folds in all 50 repeats of 10 -fold cross-validations in alphabetical order.

\begin{tabular}{lrr}
\hline Gene set & Sum score & Average score \\
\hline Adenyl Nucleotide Binding & 48.90 & 0.12 \\
Calcium lon Binding & 17.29 & 0.07 \\
Cation Transmembrane Transporter Activity & 41.22 & 0.20 \\
Cell Adhesion Molecule Binding & 22.82 & 0.12 \\
Cyclic Nucleotide Phosphodiesterase Activity & 9.47 & 0.47 \\
Cytoskeletal Protein Binding & 40.91 & 0.12 \\
DNA Binding Transcription Factor Activity & 29.30 & 0.07 \\
Double Stranded DNA Binding & 27.43 & 0.11 \\
Drug Binding & 76.04 & 0.17 \\
Enzyme Regulator Activity & 40.59 & 0.13 \\
Guanyl Nucleotide Binding & 4.41 & 0.04 \\
Hydrolase Activity Acting on Ester Bonds & 17.34 & 0.08 \\
Identical Protein Binding & 84.68 & 0.17 \\
lon Transmembrane Transporter Activity & 54.31 & 0.20 \\
Kinase Activity & 28.67 & 0.12 \\
Kinase Binding & 33.68 & 0.15 \\
Lipid Binding & 20.37 & 0.09 \\
Metal lon Transmembrane Transporter Activity & 36.13 & 0.22 \\
Molecular Function Regulator & 94.53 & 0.18 \\
Passive Transmembrane Transporter Activity & 39.66 & 0.24 \\
Phospholipid Binding & 11.15 & 0.08 \\
Phosphoric Ester Hydrolase Activity & 11.88 & 0.09 \\
Protein Containing Complex Binding & 41.43 & 0.14 \\
Protein Dimerization Activity & 61.52 & 0.15 \\
Protein Domain Specific Binding & 34.72 & 0.16 \\
Protein Homodimerization Activity & 43.86 & 0.16 \\
Protein Kinase Activity & 26.48 & 0.14 \\
Protein Serine Threonine Tyrosine Kinase Activity & 0.00 & 0.00 \\
Ribonucleotide Binding & 54.52 & 0.11 \\
Sequence Specific DNA Binding & 29.52 & 0.10 \\
Sequence Specific Double Stranded DNA Binding & 27.43 & 0.12 \\
Signaling Receptor Binding & 112.30 & 0.23 \\
Structural Molecule Activity & 15.38 & 0.08 \\
Transcription Coregulator Activity & 14.42 & 0.10 \\
Transferase Activity Transferring Phosphorus Containing Groups & 28.67 & 0.11 \\
Transition Metal lon Binding & 39.35 & 0.14 \\
Transmembrane Transporter Activity & 55.37 & 0.17 \\
Transporter Activity & 62.13 & 0.16 \\
Zinc lon Binding & 22.77 & 0.11 \\
\hline & & \\
& & \\
& &
\end{tabular}


bioRxiv preprint doi: https://doi org/10.1101/2020.05.15.099028; this version posted May 16, 2020. The copyright holder for this preprint (which was not certified by peer review) is the author/funder, who has granted bioRxiv a license to display the preprint in perpetuity. It is made available under aCC-BY-NC-ND 4.0 International license.

Table S5: Gene ontology biological process gene sets with a prioritisation score in top $5 \%$ in all ten folds in all 50 repeats of 10 -fold cross-validations in alphabetical order.

\begin{tabular}{|c|c|c|}
\hline Gene set & Sum score & Average score \\
\hline $\begin{array}{l}\text { Acute Inflammatory Response } \\
\text { Amyloid Precursor Protein Metabolic Process } \\
\text { Artery Development } \\
\text { Axis Specification } \\
\text { Catecholamine Secretion }\end{array}$ & $\begin{array}{r}10.40 \\
10.90 \\
1.99 \\
2.10 \\
15.76\end{array}$ & $\begin{array}{l}0.36 \\
0.44 \\
0.07 \\
0.08 \\
0.58\end{array}$ \\
\hline $\begin{array}{l}\text { Cell Adhesion Mediated by Integrin } \\
\text { Cell Differentiation Involved in Kidney Development } \\
\text { Cellular Response to Heat } \\
\text { Cellular Response to Lipoprotein Particle Stimulus } \\
\text { Cerebral Cortex Cell Migration }\end{array}$ & $\begin{array}{l}0.94 \\
2.09 \\
6.69 \\
2.97 \\
9.61\end{array}$ & $\begin{array}{l}0.03 \\
0.10 \\
0.22 \\
0.30 \\
0.42\end{array}$ \\
\hline $\begin{array}{l}\text { Diencephalon Development } \\
\text { DNA Damage Response Signal Transduction by P53 Class Mediator } \\
\text { Embryonic Heart Tube Development } \\
\text { Embryonic Pattern Specification } \\
\text { Epithelial Cell Apoptotic Process }\end{array}$ & $\begin{array}{l}9.94 \\
2.57 \\
0.00 \\
6.79 \\
1.64\end{array}$ & $\begin{array}{l}0.37 \\
0.10 \\
0.00 \\
0.27 \\
0.06\end{array}$ \\
\hline $\begin{array}{l}\text { Fibroblast Growth Factor Receptor Signaling Pathway } \\
\text { Forebrain Generation of Neurons } \\
\text { Forebrain Neuron Differentiation } \\
\text { Glomerulus Development } \\
\text { Inner Ear Morphogenesis }\end{array}$ & $\begin{array}{r}5.72 \\
12.53 \\
11.31 \\
1.28 \\
5.27\end{array}$ & $\begin{array}{l}0.21 \\
0.42 \\
0.44 \\
0.05 \\
0.18\end{array}$ \\
\hline $\begin{array}{l}\text { Multi Organism Behavior } \\
\text { Muscle Cell Migration } \\
\text { Myeloid Cell Development } \\
\text { Negative Regulation of Extrinsic Apoptotic Signaling Pathway } \\
\text { Negative Regulation of Fat Cell Differentiation }\end{array}$ & $\begin{array}{r}13.45 \\
2.60 \\
6.77 \\
8.95 \\
1.02\end{array}$ & $\begin{array}{l}0.50 \\
0.11 \\
0.26 \\
0.30 \\
0.06\end{array}$ \\
\hline $\begin{array}{l}\text { Negative Regulation of Hormone Secretion } \\
\text { Negative Regulation of Ossification } \\
\text { Negative Regulation of Protein Polymerization } \\
\text { Neural Crest Cell Migration } \\
\text { Neuroblast Proliferation }\end{array}$ & $\begin{array}{r}9.61 \\
0.87 \\
3.24 \\
8.85 \\
11.05\end{array}$ & $\begin{array}{l}0.34 \\
0.03 \\
0.12 \\
0.34 \\
0.38\end{array}$ \\
\hline $\begin{array}{l}\text { Neuron Fate Commitment } \\
\text { Neuron Recognition } \\
\text { Odontogenesis of Dentin Containing Tooth } \\
\text { Osteoclast Differentiation } \\
\text { Pigmentation }\end{array}$ & $\begin{array}{l}8.40 \\
7.99 \\
0.00 \\
0.87 \\
9.25\end{array}$ & $\begin{array}{l}0.32 \\
0.27 \\
0.00 \\
0.03 \\
0.32\end{array}$ \\
\hline $\begin{array}{l}\text { Platelet Derived Growth Factor Receptor Signaling Pathway } \\
\text { Positive Regulation of Actin Filament Bundle Assembly } \\
\text { Positive Regulation of Animal Organ Morphogenesis } \\
\text { Positive Regulation of Cell Cycle Phase Transition } \\
\text { Positive Regulation of DNA Metabolic Process }\end{array}$ & $\begin{array}{l}0.96 \\
2.03 \\
5.30 \\
2.05 \\
0.00\end{array}$ & $\begin{array}{l}0.06 \\
0.08 \\
0.20 \\
0.09 \\
0.00\end{array}$ \\
\hline $\begin{array}{l}\text { Positive Regulation of Mitotic Cell Cycle } \\
\text { Positive Regulation of Muscle Tissue Development } \\
\text { Positive Regulation of Peptide Hormone Secretion } \\
\text { Positive Regulation of Protein Binding } \\
\text { Positive Regulation of Regulated Secretory Pathway }\end{array}$ & $\begin{array}{r}8.97 \\
17.21 \\
3.90 \\
11.11 \\
2.91\end{array}$ & $\begin{array}{l}0.31 \\
0.82 \\
0.14 \\
0.38 \\
0.13\end{array}$ \\
\hline
\end{tabular}


bioRxiv preprint doi: https://doi org/10.1101/2020.05.15.099028; this version posted Mav 16. 2020. The copyriaht holder for this preprin (which was not certified by peer review) is the author/funder, who has granted bioRxiv a license to display the preprint in perpetuity. It is made available under aCC-BY-NC-ND 4.0 International license.

Table S5: (Continued) Gene ontology biological process gene sets with a prioritisation score in top $5 \%$ in all ten folds in all 50 repeats of 10 -fold cross-validations in alphabetical order.

\begin{tabular}{lrr}
\hline Gene set & Sum score & Average score \\
\hline Post Embryonic Development & 8.61 & 0.30 \\
Proteoglycan Biosynthetic Process & 2.95 & 0.11 \\
Regulation of Adherens Junction Organization & 0.96 & 0.03 \\
Regulation of Cardiac Muscle Tissue Development & 21.31 & 0.79 \\
Regulation of Cartilage Development & 1.06 & 0.04 \\
Regulation of Cellular Ketone Metabolic Process & 4.37 & 0.15 \\
Regulation of Chondrocyte Differentiation & 1.06 & 0.05 \\
Regulation of Filopodium Assembly & 3.58 & 0.14 \\
Regulation of Jun Kinase Activity & 4.80 & 0.19 \\
Regulation of Kidney Development & 3.37 & 0.18 \\
Regulation of Muscle Adaptation & 8.83 & 0.29 \\
Regulation of Neuronal Synaptic Plasticity & 11.04 & 0.39 \\
Regulation of Protein Targeting & 3.29 & 0.12 \\
Regulation of Protein Tyrosine Kinase Activity & 22.48 & 0.75 \\
Regulation of Smooth Muscle Contraction & 8.19 & 0.27 \\
Regulation of Stem Cell Proliferation & 5.20 & 0.19 \\
Response to Amino Acid & 11.30 & 0.45 \\
Response to Anesthetic & 24.53 & 0.88 \\
Response to Nerve Growth Factor & 13.77 & 0.55 \\
Response to Vitamin & 3.06 & 0.11 \\
Signal Transduction in Absence of Ligand & 6.55 & 0.25 \\
Signal Transduction in Response to DNA Damage & 2.57 & 0.09 \\
Smooth Muscle Cell Migration & 2.60 & 0.14 \\
Sterol Transport & 2.08 & 0.08 \\
Ventricular Septum Development & 1.93 & 0.07 \\
\hline
\end{tabular}

Table S6: AUC of the corresponding ROC curve when interpreting glmnet functional edge selection results by each GSC with each post-hoc interpretability metric.

\begin{tabular}{lrrrr}
\hline Gene set collection & Jaccard & Jacard P-value & Edge betweenness & Edge betweenness P-value \\
\hline TFT & 0.56 & 0.55 & 0.56 & 0.57 \\
KEGG & 0.66 & 0.67 & 0.58 & 0.56 \\
REACTOME & 0.63 & 0.63 & 0.59 & 0.57 \\
GO-BP & 0.59 & 0.59 & 0.60 & 0.59 \\
GO-CC & 0.58 & 0.58 & 0.57 & 0.56 \\
GO-MF & 0.66 & 0.66 & 0.64 & 0.63 \\
Positional & 0.51 & 0.48 & 0.37 & 0.40 \\
Immunological & 0.50 & 0.50 & 0.52 & 0.52 \\
\hline
\end{tabular}


bioRxiv preprint doi: https://doi.org/10.1101/2020 05.15.099028; this version posted May 16, 2020. The copyright holder for this preprint (which was not certified by peer review) is the author/funder, who has granted bioRxiv a license to display the preprint in perpetuity. It is made available under aCC-BY-NC-ND 4.0 International license.

Table S7: AUC of the corresponding ROC curve when interpreting graphclass functional edge selection results by each GSC with each post-hoc interpretability metric.

\begin{tabular}{lrrrr}
\hline Gene set collection & Jaccard & Jacard P-value & Edge betweenness & Edge betweenness P-value \\
\hline TFT & 0.54 & 0.55 & 0.60 & 0.62 \\
KEGG & 0.52 & 0.53 & 0.55 & 0.52 \\
REACTOME & 0.63 & 0.64 & 0.57 & 0.55 \\
GO-BP & 0.53 & 0.53 & 0.64 & 0.62 \\
GO-CC & 0.51 & 0.51 & 0.63 & 0.59 \\
GO-MF & 0.58 & 0.58 & 0.68 & 0.64 \\
Positional & 0.54 & 0.56 & 0.39 & 0.44 \\
Immunological & 0.49 & 0.49 & 0.52 & 0.50 \\
\hline
\end{tabular}

